\title{
Wind Gust Characterization at Wind Turbine Relevant Heights in Moderately Complex Terrain
}

\author{
W. HU AND F. LETSON \\ Department of Earth and Atmospheric Sciences, and Sibley School of Mechanical and Aerospace Engineering, \\ Cornell University, Ithaca, New York \\ R. J. BARTHELMIE \\ Sibley School of Mechanical and Aerospace Engineering, Cornell University, Ithaca, New York \\ S. C. PRYOR \\ Department of Earth and Atmospheric Sciences, Cornell University, Ithaca, New York
}

(Manuscript received 10 February 2018, in final form 23 April 2018)

\begin{abstract}
Improved understanding of wind gusts in complex terrain is critically important to wind engineering and specifically the wind energy industry. Observational data from 3D sonic anemometers deployed at 3 and $65 \mathrm{~m}$ at a site in moderately complex terrain within the northeastern United States are used to calculate 10 descriptors of wind gusts and to determine the parent distributions that best describe these parameters. It is shown that the parent distributions exhibit consistency across different descriptors of the gust climate. Specifically, the parameters that describe the gust intensity (gust amplitude, rise magnitude, and lapse magnitude; i.e., properties that have units of length per time) fit the two-parameter Weibull distribution, those that are unitless ratios (gust factor and peak factor) are described by log-logistic distributions, and all other properties (peak gust, rise and lapse times, gust asymmetric factor, and gust length scale) are lognormally distributed. It is also shown that gust factors scale with turbulence intensity, but gusts are distinguishable in power spectra of the longitudinal wind component (i.e., they have demonstrably different length scales than the average eddy length scale). Gust periods at the lower measurement height $(3 \mathrm{~m})$ are consistent with shear production, whereas at $65 \mathrm{~m}$ they are not. At this site, there is only a weak directional dependence of gust properties on site terrain and land cover variability along sectorial transects, but large gust length scales and gust factors are more likely to be observed in unstable atmospheric conditions.
\end{abstract}

\section{Introduction}

Wind gusts are coherent (transient) features within a turbulent wind field that are characterized by short-term wind speed increases. In the boundary layer, the dominant length scales, and magnitude, of turbulent fluctuations and the presence and characteristics of intermittent coherent features such as gusts depend on factors such as surface roughness, landscape patchiness, and topographical complexity, in addition to the stability and mesoscale climate (Ágústsson and Ólafsson 2004; Brasseur 2001; Burton et al. 2011; Mason et al. 2010; Suomi et al. 2013).

Because the aerodynamic force exerted by the wind scales with the square of the wind speed, wind gusts are

\footnotetext{
Corresponding author: Weifei Hu,wh348@cornell.edu
}

an important component of structural loads (Kwon and Kareem 2009) and also are relevant to natural hazards [e.g., forest fire damage (Taylor et al. 2004) and wind throw (Dupont et al. 2015)], as well as traffic and aviation safety (Boettcher et al. 2003; Chan 2012). There has been substantial progress in methods for determining spatial wind gust climatologies, and maps of intense and extreme gusts have been developed for the contiguous United States (e.g., ASCE 2010; Letson et al. 2018; Simiu et al. 2003; Vickery et al. 2010). However, these efforts have tended to focus on the absolute magnitudes of 3- or 5-s moving average wind speeds at various return period intervals, and fewer studies have focused on other properties of wind gusts (e.g., their temporal structure at high frequencies, length scales, and spatial coherence). 
There are no unique and consistent definitions for identifying wind gust events and for characterizing their magnitude (intensity) and/or duration. When identifying gust events, the typical moving average window $t$ and sampling period $T$ vary by application [e.g., aviation (Young and Kristensen 1992) and wind energy (Burton et al. 2011; Hu et al. 2016)]. A moving window of $t=3 \mathrm{~s}$ within an integration period $T$ of $10 \mathrm{~min}$ is suggested by the World Meteorological Organization (WMO 2012) and is typically used for structural and fatigue analyses (Hu et al. 2016). Kwon and Kareem (2009) suggest that using $t=3 \mathrm{~s}$ in the American Society of Civil Engineers (ASCE) 7 procedure leads to a slightly conservative design for flexible building structures, whereas it has been suggested that using $T>10 \mathrm{~min}$ may be appropriate for extratropical synoptic systems (Holmes et al. 2014). In practice, the National Weather Service (NWS) Automated Surface Observing System (ASOS) network reports wind gusts under the criteria that they are $\geq 3 \mathrm{kt}\left(1 \mathrm{kt}=0.51 \mathrm{~m} \mathrm{~s}^{-1}\right)$ above the current 2-min mean wind speed (which must be $>2 \mathrm{kt}$ ) and $\geq 10 \mathrm{kt}$ or more than the minimum 3-s wind speed in the past $10 \mathrm{~min}$ (Hu et al. 2017; NOAA 1998, 2004).

The specific gust properties of primary interest are dependent on the specific application. In the following bullets, we illustrate examples of how different descriptors of wind gusts are employed within the wind energy industry:

- Large magnitude wind gusts that occur above wind turbine (WT) cut-in wind speeds induce high loads and contribute to blade fatigue particularly via the gust slicing effect (i.e., a blade slices through a gust repeatedly over the course of several revolutions; Burton et al. 2011). As an illustration of the structural loading on a WT due to gusts, Fig. 1 shows measured drivetrain acceleration $A_{D}$ and tower acceleration $A_{T}$ from a WT operating at the study site considered herein, conditionally sampled by 10-min mean wind speed and the occurrence and intensity of wind gusts. As shown, both the drivetrain and the tower acceleration are consistently higher during 10 -min periods characterized by strong gust events (i.e., gust amplitude $\geq 5 \mathrm{~m} \mathrm{~s}^{-1}$ ) than those in 10-min periods with no or only low-magnitude gust events (i.e., gust amplitude $<5 \mathrm{~m} \mathrm{~s}^{-1}$ ). Indeed, the median WT drivetrain and tower accelerations are $11 \%$ and $54 \%$ higher, respectively, in the presence of large gust amplitudes. Further, probability distributions of $A_{D}$ and $A_{T}$ under strong gust conditions indicate higher probabilities of large structural deformation.

- Typically, gusts located in the upper tail of the probability distribution (i.e., events with large amplitude) are of particular interest because they are likely to cause extreme loads and dynamical response from structures (Suomi et al. 2013). It is customary to base extreme load cases for both operating and nonoperating WTs on the 50-yr return period 3-s gust at WT hub height (Germanischer Lloyd 2010; International Electrotechnical Commission 2005). Extrapolation of relatively short observational data records to these long return periods usually employs either annual/ monthly maximum observations fitted to a Gumbel distribution or approximations linking the extreme gust to the mean wind speed and site turbulence intensity. This extrapolation might be enabled by more accurately describing the parent probability distribution of wind gust speeds and linking the distribution parameters of the parent distribution to those from the appropriate associated generalized extreme value distribution (e.g., there is a robust association between the Weibull distribution parameters and those of the Gumbel distribution that have been applied to assess extreme sustained wind speeds; Pryor et al. 2012).

- Turbulence intensity and wind gust magnitudes are typically larger in inhomogeneous terrain and land use/land cover (Tieleman 1992; Verheij et al. 1992). Accordingly, within the wind energy industry standards simple analytical forms have been developed and applied, linking an estimate of local roughness length $z_{0}$ to likely turbulence intensity and specifying the $t$-second gust factor. For example, the Danish standard (DS 472; Danish Society of Engineers 1992; now superseded) used $I_{u}=1.0 / \ln \left(z, z_{0}\right)$ and the gust factor (for a given integration period $t$ ) has frequently been specified as $G_{t, T}=1+0.42 I_{u} \ln (3600 / t)$ (Burton et al. 2011).

- In WT-design cases under extreme and fatigue loading, it is often assumed that the time evolution of wind gusts can be characterized using a canonical Mexicanhat shape (Germanischer Lloyd 2010; International Electrotechnical Commission 2005; Manwell et al. 2010), because an analytical function for a perfectly symmetric Mexican hat can be applied to assess the critical wind speed (Hu et al. 2013; Larsen and Hansen 2004). However, as documented herein and noted in previous research (Bierbooms and Cheng 2002), observations tend to deviate markedly from this assumed form, which may potentially lead to misspecification of extreme aerodynamic loads.

- There is evidence that the most damaging wind gusts are those manifesting at a scale at which they engulf the entire structure or have length scales less than the dimensions of the structure but are of similar scale (Beljaars 1987; Frost and Turner 1982; Greenway 1979). Hence, the dominant turbulence and gust length scales are also frequently considered in the structural design processes for WTs (International Electrotechnical Commission 2005). Identifying the best-fit distribution for the gust length scale may therefore benefit 

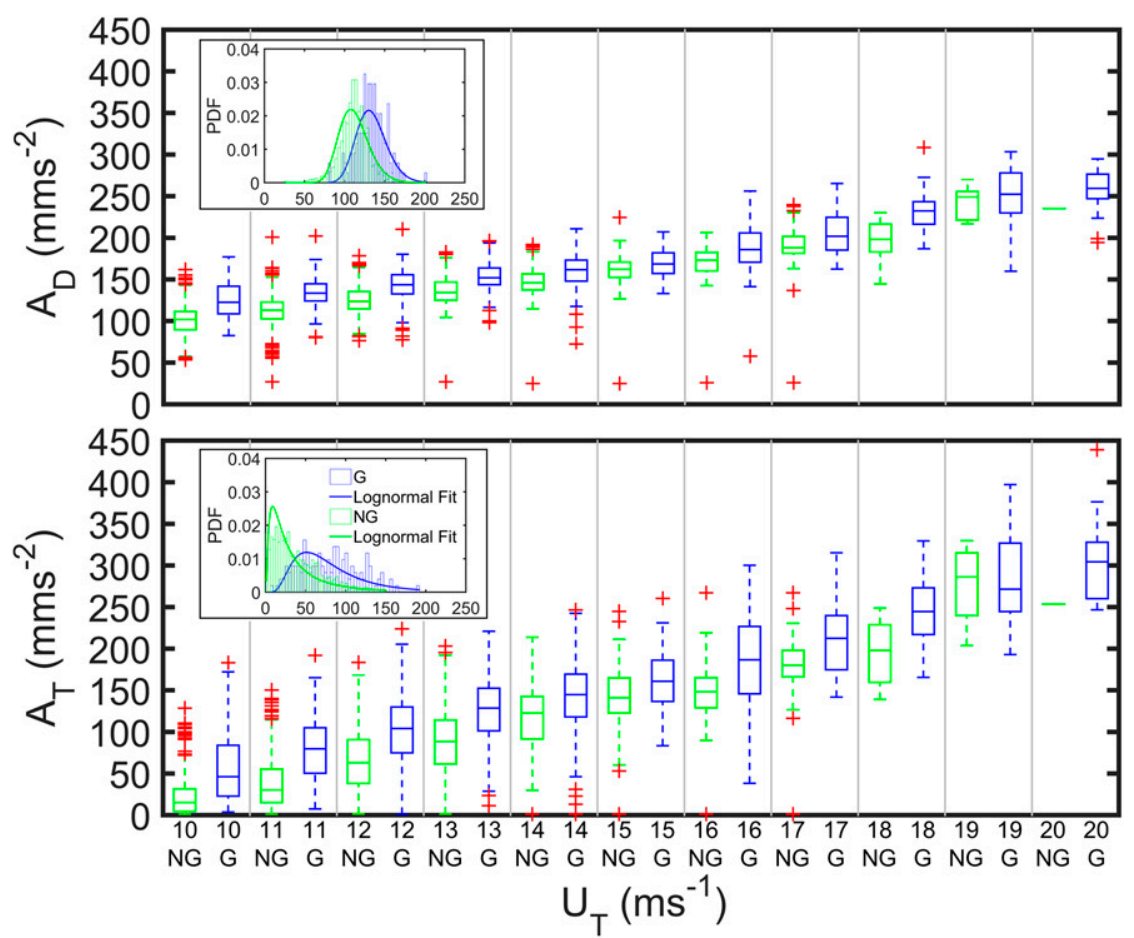

FIG. 1. Boxplots of 10-min mean WT drivetrain acceleration $A_{D}$ and tower acceleration $A_{T}$ from the supervisory control and data acquisition system on a WT $(\sim 222 \mathrm{~m}$ from the meteorological mast) conditionally sampled by 10 -min mean wind speed from the sonic anemometer deployed at $65 \mathrm{~m}$ (i.e., WT hub height). The label " $\mathrm{G}$ " denotes 10 -min periods in which strong gusts were observed (i.e., gust amplitude $\geq 5 \mathrm{~m} \mathrm{~s}^{-1}$ ) while NG denotes data collected during 10 -min periods with "mild" gusts (i.e., gust amplitude $<5 \mathrm{~m} \mathrm{~s}^{-1}$ ). The red plus signs indicate values that are $>1.5$ times the IQR above the 75 th percentile or below the 25 th percentile values, respectively. The insets in each panel show the histograms and lognormal distribution fits to $A_{D}$ and $A_{T}$ for 10-min mean wind speeds $=11( \pm 0.5) \mathrm{m} \mathrm{s}^{-1}$.

reliability analyses (Beljaars 1987; Frost and Turner 1982; Greenway 1979).

This brief précis thus illustrates the diversity of wind gust descriptors required to describe the aerodynamic design loads for WTs and provides a motivation for their investigation. This paper reports wind measurements conducted in an area of moderately complex terrain in the northeastern United States and analyzes them in order to do the following:

1) Describe the probability distributions that most accurately represent different metrics of wind gusts (e.g., gust amplitude, length scales, and rise and lapse times).

2) Evaluate parameterizations used to predict the gust factor and peak factor (i.e., $G_{t, T}$ and $k_{t, T}$ ) as a function of the mean sustained wind speed and turbulence intensity.

3) Examine the degree to which wind gust signatures are differentiable in turbulence spectra. Improved simulation of a gust event of given characteristics while controlling the statistical properties of the simulated time series is necessary to derive a more accurate constrained stochastic simulation of wind loading events (Bierbooms 2005; Burton et al. 2011).

4) Examine the dependence of different descriptors of wind gusts on terrain characteristics and atmospheric stability. Previous research has proposed simple analytical models linking turbulence intensity and gust magnitudes to a descriptor of a regional roughness length that takes account of upwind terrain roughness and topography (Ashcroft 1994). Herein we explore an alternative methodology that links the metrics of landscape complexity to wind gust magnitudes and length scales and further investigate the dependence of gust parameters on atmospheric stability in different directional sectors.

\section{Measurements and data}

The measurements presented herein were conducted using two Gill Windmaster Pro 3D sonic anemometers deployed on a $65-\mathrm{m}$ meteorological mast located in 

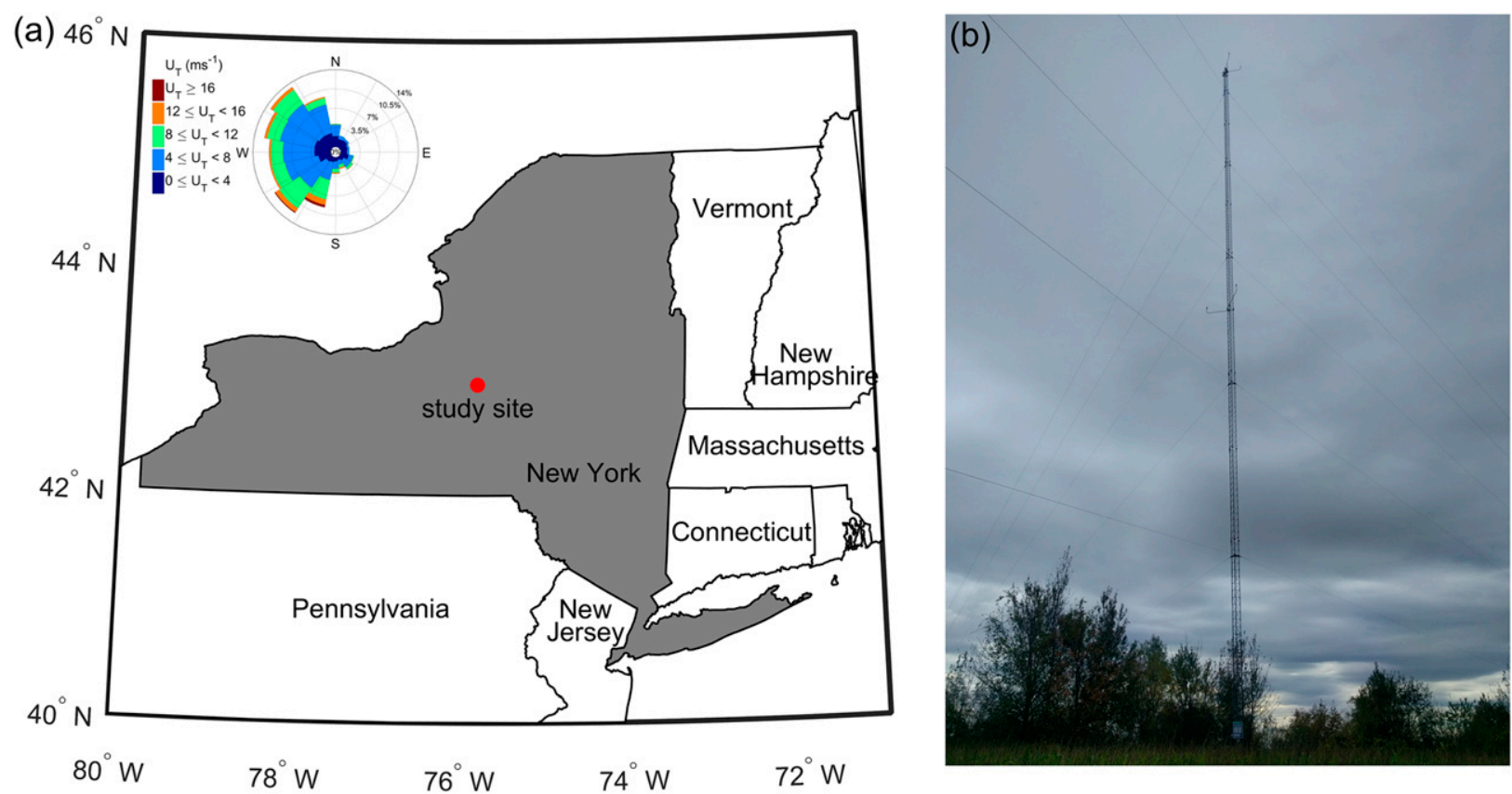

(c)

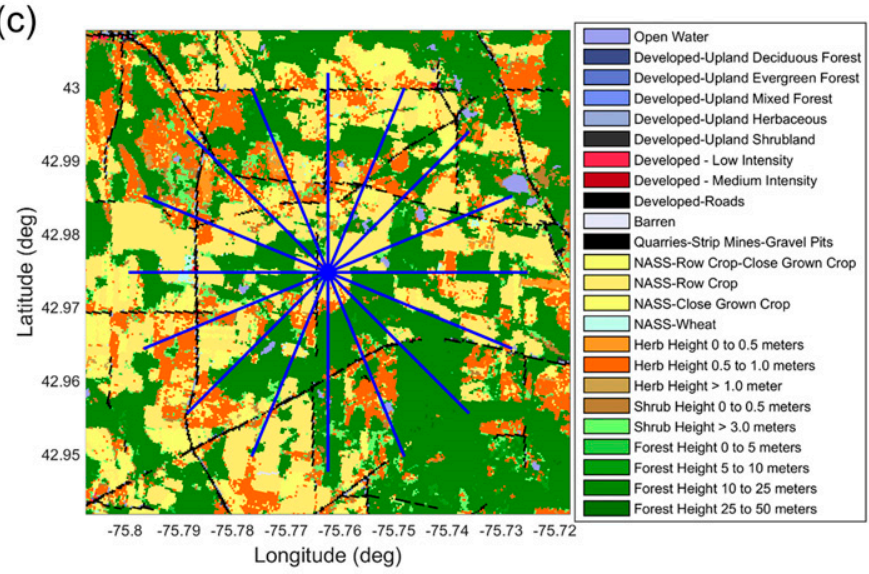

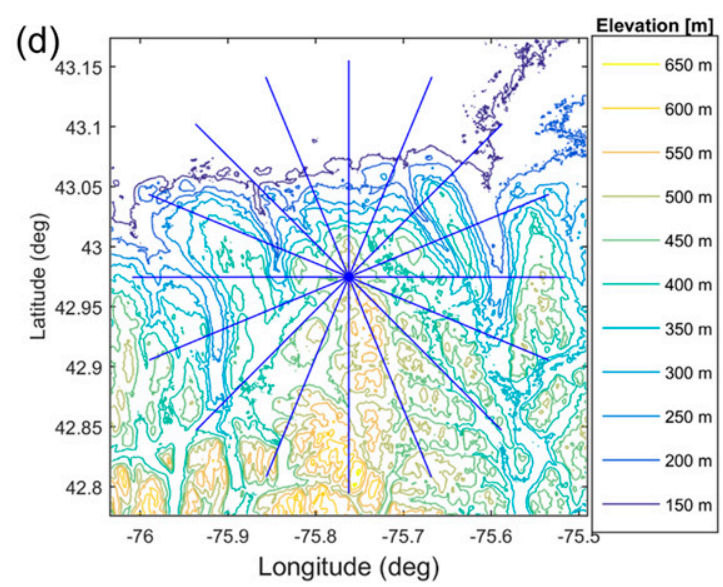

FIG. 2. (a) Location of the measurement site, along with (b) a photograph of the 65-m meteorological mast on which data were collected. In (a) a wind rose is also shown for all 10-min sustained wind speeds as measured at $65 \mathrm{~m}$. (c),(d) Maps show land use from the LANDFIRE dataset (https://www.usna.edu/Users/oceano/pguth/md_help/html/veg_grid.htm) and terrain elevation from the SRTM (http://www2.jpl. nasa.gov/srtm/), respectively, along with the 16 transects.

moderately complex terrain in a landscape dominated by row crops but with patches of forest and small lakes (at approximately $43.0^{\circ} \mathrm{N}, 75.8^{\circ} \mathrm{W}, 510 \mathrm{~m}$ above mean sea level; Fig. 2). The meteorological mast is a triangular lattice tower with $0.43-\mathrm{m}$ face width. One sonic anemometer was deployed $1.52 \mathrm{~m}$ from the closest leg on a guyed boom oriented west of the mast at a height above ground level of $2.74 \mathrm{~m}$ (referred to herein as $3 \mathrm{~m}$ ). Given the importance of structural flow distortion to measurements on meteorological masts (Munger et al. 2012), observations that form the basis of most of the analyses presented herein derive from a second sonic anemometer deployed on a 4-m boom extending $1.4 \mathrm{~m}$ above the top of the mast (referred to herein as $65 \mathrm{~m}$ ). Mounting above the top of a meteorological mast (as in our measurements at $65 \mathrm{~m}$ ) has been described as optimal and resulting in flow distortion $<2 \%$ when anemometers are deployed (as here) $>2$ times the width of the tower, above the tower (Lubitz 2009). Three wind components (longitudinal speed $u$, transverse speed $v$, and vertical speed $w$ ) from these two systems were recorded at $10 \mathrm{~Hz}$ from May 2016 to October 2017. The resulting time series are discretized into 10-min intervals. The mean sustained wind speed at $65 \mathrm{~m}$ exhibits a dominance of flow from the westerly sector (Fig. 2a). Following prior research (Suomi et al. 2013), in order to reduce the 
confounding effects of high gust factors at low wind speeds, all analyses presented below represent 10-min periods wherein the mean wind speed at $65 \mathrm{~m}$ exceeds $3 \mathrm{~m} \mathrm{~s}^{-1}$.

To study the influence of landscape features on gust characteristics, terrain elevation data with 30-m horizontal resolution from the Shuttle Radar Topography Mission (SRTM) are used to characterize terrain complexity (Farr et al. 2007; available at http://www2.jpl.nasa.gov/srtm/). Land cover characteristics including vegetation height, also at 30-m resolution, are retrieved from the Landscape Fire and Resource Management Planning Tools (LANDFIRE) dataset (available at https://www.usna. edu/Users/oceano/pguth/md_help/html/veg_grid.htm).

\section{Definitions and methods}

This section first provides the definitions of the gust descriptors analyzed herein and then explains the detailed methods used to characterize gusts. A list of parameters and definitions used in this paper is provided in the appendix.

\section{a. Definitions of the gust descriptors analyzed herein}

Following World Meteorological Organization recommendations, herein the peak wind gust $u_{t, T}^{\max }$ is defined as the maximum 3-s moving average longitudinal wind speed $u$ during each $10-$ min period (WMO 2012). The gust amplitude is described as the difference between that peak 3-s running mean gust speed and 10-min mean wind speed $U_{T}$,

$$
u_{t, T}^{a}=u_{t, T}^{\max }-U_{T},
$$

while the gust factor $G_{t, T}$ is defined as the ratio of the peak gust $u_{t, T}^{\max }$ to the mean wind speed $U_{T}$ :

$$
G_{t, T}=\frac{u_{t, T}^{\max }}{U_{T}} .
$$

The peak factor $k_{t, T}$ is defined as the ratio of the gust amplitude $u_{t, T}^{a}$ to the standard deviation $\sigma_{T}$ of 10-min wind speed:

$$
k_{t, T}=\frac{u_{t, T}^{a}}{\sigma_{T}} .
$$

By incorporating the turbulence intensity $I_{T}\left(I_{T}=\right.$ $\left.\sigma_{T} / U_{T}\right)$, the relationship between gust factor and peak gust can be easily derived as

$$
G_{t, T}=1+k_{t, T} I_{T} .
$$

The evolution of discrete gust events within a time series of $u$ is characterized by four parameters: rise time $t_{r}$ (time from the start-valley to the peak of a gust), lapse time $t_{l}$ (time from the peak to the end-valley), rise magnitude $u_{r}$ (wind speed difference from the startvalley to the peak), and lapse magnitude $u_{l}$ (wind speed difference from the peak to the end-valley; see Fig. 3). From these a gust asymmetric factor (GAF) is derived:

$$
\mathrm{GAF}=\frac{u_{r} / t_{r}}{u_{l} / t_{l}}
$$

The gust length scale $L_{g}$ is calculated by integrating the 3-s moving average wind speed $u_{t, T}$ over the whole gust period:

$$
L_{g}=\int_{t_{\mathrm{sv}}}^{t_{\mathrm{ev}}} u_{t, T}(t) d t
$$

where $t_{\mathrm{sv}}$ and $t_{\mathrm{ev}}$ correspond to the time at the startvalley and end-valley of a gust event (Fig. 3). Note here that we define the gust time period from $t_{\mathrm{sv}}$ to $t_{\mathrm{ev}}$, not from the crossing times of $U_{T}$ (Fig. 3). This ensures we fully encapsulate the entire period over which flow acceleration and deceleration is experienced. The average turbulent length scale $L_{t}$ is derived from both spectral fits to the data (see example in Fig. 3) and also derived by multiplying the mean wind speed $U_{T}$ by the integral of the autocorrelation function (ACF) of $u$ (Camp and Shin 1995):

$$
L_{t}=U_{T} \int_{0}^{\infty} \operatorname{ACF}(\tau) d \tau
$$

where the ACF is expressed as

$$
\operatorname{ACF}(\tau)=\frac{\frac{1}{\Delta T} \int_{0}^{\Delta T} u(t) u(t+\tau) d t}{\frac{1}{\Delta T} \int_{0}^{\Delta T} u^{2}(t) d t}
$$

where the time period $\Delta T$ (i.e., $10 \mathrm{~min}$ ) is significantly larger than the measured frequency (i.e., $0.1 \mathrm{~s}) ; u(t)$ is the raw wind speed measured at $10 \mathrm{~Hz}$, and $\tau$ is the time lag.

\section{b. Methods}

The methodology used to identify the best-fit probability distributions of gust parameters is explained in section $3 b(1)$, which is followed by gust parameterization methods in section $3 b(2)$. Section $3 b(3)$ examines the degree to which wind gust signatures are differentiable in turbulence spectra. Section 3b(4) explains how to link gust characteristics to landscape properties and atmospheric stability.

\section{1) StATisticAl ANALySES OF GUST PARAMETERS}

For each 10-min period, the three wind components measured by the two 3D sonic anemometers (at 3 and 
(a)
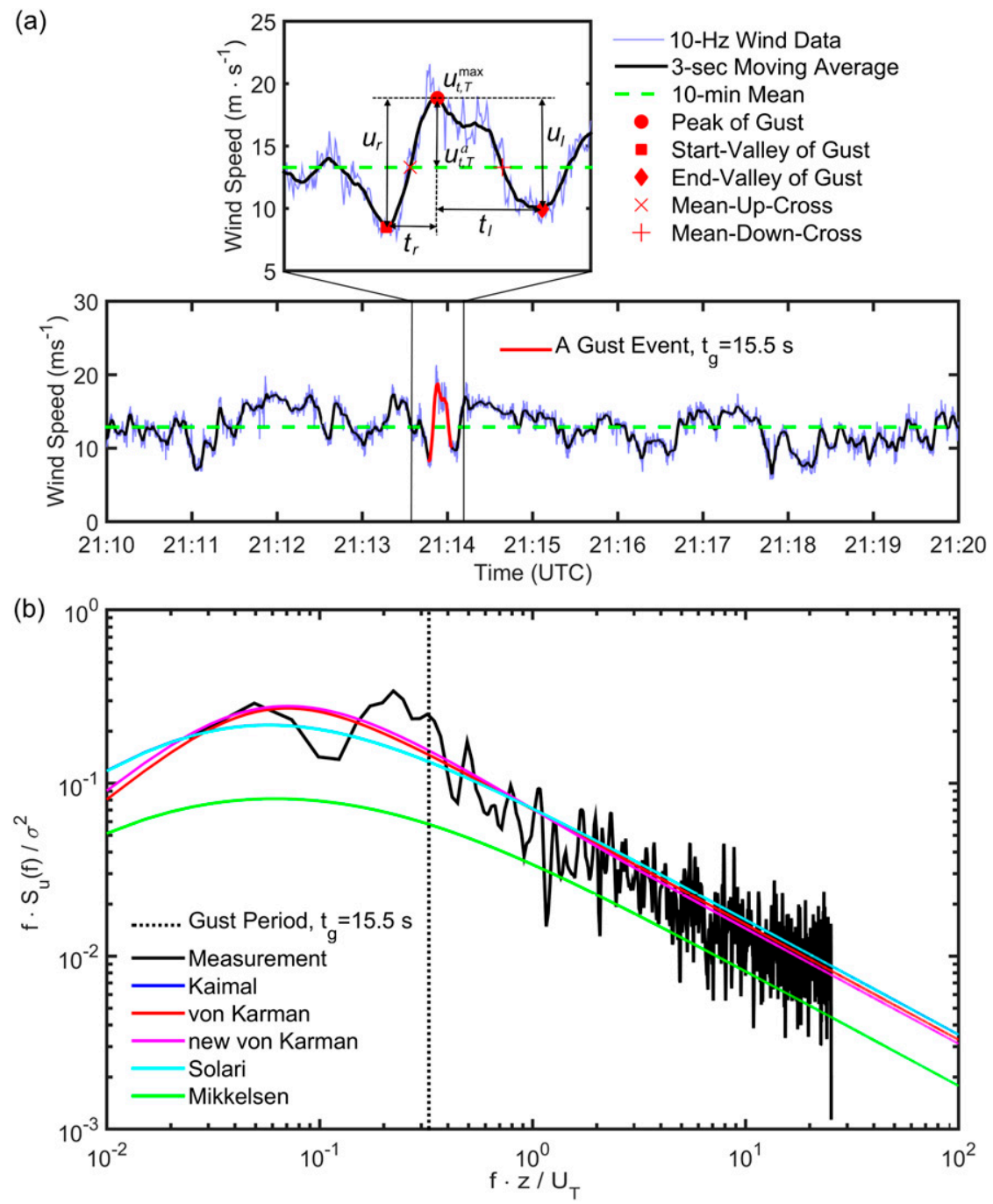

FIG. 3. (a) An illustration of a single gust event showing the gust descriptors. This 10-min case study presents conditions from 2110:00 to 2120:00 UTC 29 May 2016 at $65 \mathrm{~m}$. The mean longitudinal wind speed during a 10 -min period $U_{T}$ is shown by the green dashed line, while the blue line depicts the $10-\mathrm{Hz}$ time series $u$ and the black curve shows a 3 -s moving average $u_{t, T}$. The gust event highlighted in red is identified having a period of $15.5 \mathrm{~s}$. The peak of gust (red dot) denotes the maximum $u_{t, T}$; the start-valley (red square) is the valley prior to the gust peak; the end-valley (red diamond) is the first valley smaller than $U_{T}$ after the gust peak; the mean upcross (red x) is the point where $u_{t, T}$ up-crosses $U_{T}$ between the start-valley and the gust peak; the mean down-cross (red + ) is the point where $u_{t, T}$ down-crosses $U_{T}$ between the gust peak and the end-valley. (b) An example of gust signature in the normalized spectrum as derived directly from the observations and fitted by various turbulence spectral models: Kaimal (International Electrotechnical Commission 2005), von Kármán (Burton et al. 2011), new von Kármán (Engineering Sciences Data Unit 2001), Solari (Solari 1993), and Mikkelsen's SPS extended spectrum model (Mikkelsen et al. 2017) for this same 10-min period in (a). The vertical dotted line in (b) shows the gust period derived using $t_{g}=t_{r}+t_{l}$.

$65 \mathrm{~m})$ were subject to despiking using a five-standarddeviation filter and subject to coordinate rotation to derive $10-\mathrm{Hz}$ estimates of the longitudinal wind speed $u$, transverse wind speed $v$, and vertical wind speed $w$, as well as the mean 10-min wind speed and directions. The average ratio of the 3 -s running means of $u$, $v$, and $w$ to the overall wind vector (i.e., $\sqrt{u_{t, T}^{2}+v_{t, T}^{2}+w_{t, T}^{2}}$ ) at the gust peaks are $0.99,0.07$, and 0.05 , respectively (see Fig. 4 for histograms of deviations of the $v$ and $w$ components). Thus, herein all descriptors of the gust properties described in section 3a (peak gust, gust amplitude, gust factor, peak factor, rise magnitude, lapse magnitude, 

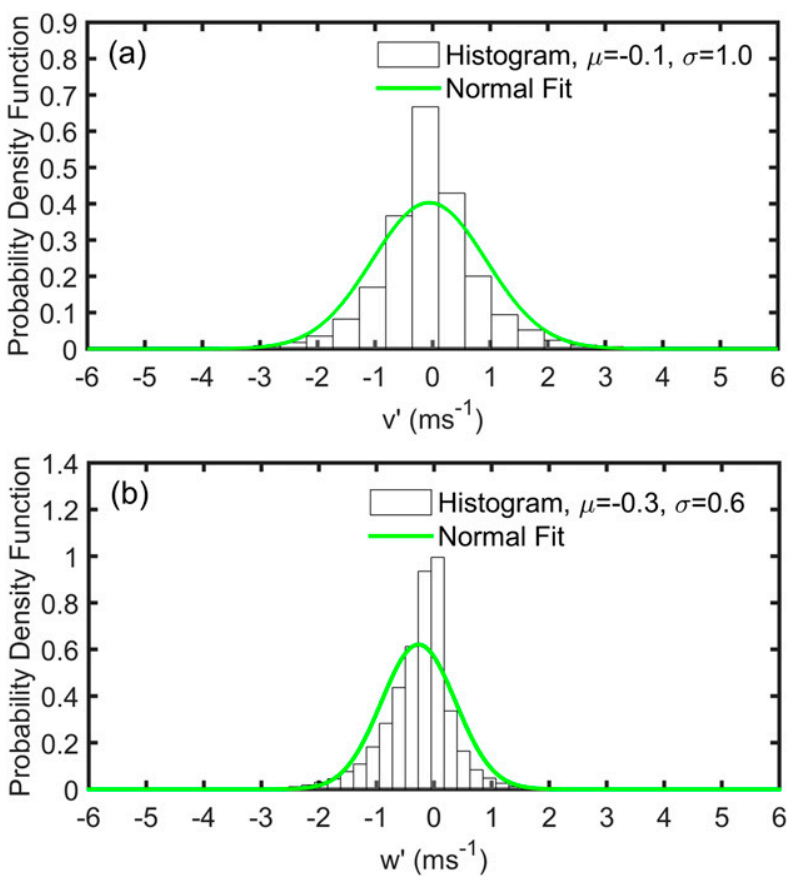

FIG. 4. Distribution of the 3-s moving average (a) transverse deviation $v^{\prime}$ and (b) vertical deviation $w^{\prime}$ at the time of the peak gust in each 10-min period when $U_{T}$ at $65 \mathrm{~m} \geq 3 \mathrm{~m} \mathrm{~s}^{-1}$. A normal distribution is also shown.

rise time, lapse time, GAF, and gust length scale) are derived using the $10-\mathrm{Hz}$ time series of $u$.

Although various probability distributions have been fitted to gust amplitudes [e.g., Rayleigh distribution (Cheng and Bierbooms 2001) and Weibull distribution (Bierbooms and Cheng 2002; Dimitrov 2016)], few previous studies have sought to address which distributional form is most appropriate, and very few have considered which parent probability distribution best represents the other gust properties [e.g., the symmetry/asymmetry of gusts (GAF)] This is an important omission given the critical role of wind gusts to extreme event simulation for WT design and the potential for gusts to distort the flow field in a way that causes them to be non-Gaussian (Nielsen et al. 2003). Since all of the gust descriptive statistics considered herein are zero bounded, four positive-valued distribution types (Weibull, lognormal, gamma, and log-logistic; see Table 1) are fitted to the 10 gust parameters using maximum likelihood estimation (MLE). The candidate distribution with the largest $\log$-likelihood $(\log L)$ value is selected as the best-fit distribution (Hogg et al. 2005).

\section{2) Gust PARAMETERIZATION METHOdS}

Numerical weather prediction (NWP) models do not resolve wind gusts explicitly, so a range of parameterizations have been developed and are applied to postprocess model output (Suomi et al. 2013). Three such analytical parameterizations for the gust factor based on the 3-s average velocity are considered herein and listed below:

(i) Greenway's expression for the gust factor based on the 3-s average velocity that is a function of turbulence intensity, mean wind speed, turbulence integral length scale, and structural size based on the assumptions of the von Kármán spectrum and the Gaussian distribution for horizontal wind velocity (Greenway 1979):

$$
G_{t, T}=1+3.25 I_{T}\left[1-8 \times 10^{-5}\left(\frac{U_{T} T}{L_{t}}\right)\right],
$$

where $I_{T}$ is the turbulence intensity, $U_{T}$ is the mean wind speed in the time period $T$, and $L_{t}$ is the integral length scale. In this approximation the gust factor is a weak function of the term $U_{T} T / L_{t}$, and thus variability in $G_{t, T}$ is dominated by $I_{T}$.

(ii) Deaves and Harris' approximation (Deaves and Harris 1976):

$$
G_{t, T}=1+3.7 I_{T}
$$

(iii) An extension of the Wieringa empirical model that relates $G_{t, T}$ to surface roughness $z_{0}$ and height $z$ and can be applied for gust wavelengths of up to approximately $200 \mathrm{~m}$ (Wieringa 1973):

$$
G_{t, T}=1+\frac{1.42+0.3013 \ln [(T / t)-4]}{\ln \left(z / z_{0}\right)} .
$$

As developed using wind data collected in a coastal region (Bardal and Sætran 2016),

$$
G_{t, T}=1+I_{T}\left[1.42+0.3013 \ln \left(\frac{T}{t}-4\right)\right],
$$

where $t$ is the moving-average time window used to compute the peak gust.

As shown above, most formulations indicate a linear relationship between the gust factor and the turbulence intensity. Gust factors and peak factors calculated using Eqs. (2) and (3) as applied to our data are compared with estimates from these previous formulations and used to derive best-fit linear relationships [and 99\% confidence intervals (CIs)] with the mean wind speed and turbulence intensity.

\section{3) ANALYZING GUST SignATURES IN TURBULENCE SPECTRAL MODELS}

Spectral models of atmospheric turbulent fields [e.g., the Kaimal spectrum (International Electrotechnical Commission 2005), von Kármán spectrum (Burton et al. 2011), new von Kármán spectrum (Engineering Sciences Data Unit 2001), and Solari spectrum (Solari 1993); see 
TABLE 1. The best-fit distributional form and coefficients ( $a$ and $b$ ) for 10 gust parameters based on data collected at $65 \mathrm{~m}$ at a site in moderately complex terrain in the northeastern United States over 18 months for all 10-min periods in which $U_{T} \geq 3 \mathrm{~m} \mathrm{~s}^{-1}$ (total number of 10-min periods of wind data used in this study is $n=40579)$. The distributional fits and empirical histograms are shown in Fig. 5.

\begin{tabular}{|c|c|c|c|}
\hline Gust parameter (unit) & Best-fit distribution type & Probability de & nsity function \\
\hline Peak gust $\left(\mathrm{m} \mathrm{s}^{-1}\right)$ & Lognormal & $f(x \mid a, b)=\frac{1}{x b \sqrt{2 \pi}} \exp \left[\frac{-(1 \mathrm{n} x-a)^{2}}{2 b^{2}}\right]$ & $a=2.13, b=0.41$ \\
\hline Gust amplitude $\left(\mathrm{m} \mathrm{s}^{-1}\right)$ & Weibull & $f(x \mid a, b)=\frac{b}{a}\left(\frac{x}{a}\right)^{b-1} \exp \left[-\left(\frac{x}{a}\right)^{b}\right], \quad a$ & $a=2.49, b=1.55$ \\
\hline Gust factor (unitless) & Log-logistic & $f(x \mid a, b)=\frac{1}{b} \frac{1}{x} \frac{\exp (z)}{[1+\exp (z)]^{2}}, \quad$ where & $z=\frac{\ln (x)-a}{b}, \quad a=0.27, b=0.07$ \\
\hline Peak factor (unitless) & Log-logistic & $f(x \mid a, b)=\frac{1}{b} \frac{1}{x} \frac{\exp (z)}{[1+\exp (z)]^{2}}, \quad$ where & $z=\frac{\ln (x)-a}{b}, \quad a=0.83, b=0.11$ \\
\hline Rise magnitude $\left(\mathrm{m} \mathrm{s}^{-1}\right)$ & Weibull & $f(x \mid a, b)=\frac{b}{a}\left(\frac{x}{a}\right)^{b-1} \exp \left[-\left(\frac{x}{a}\right)^{b}\right]$ & $a=3.12, b=1.51$ \\
\hline Lapse magnitude $\left(\mathrm{m} \mathrm{s}^{-1}\right)$ & Gamma & $f(x \mid a, b)=\frac{1}{b^{a} \Gamma(a)} x^{a-1} \exp \left[-\left(\frac{x}{b}\right)\right]$ & $a=2.24, b=1.20$ \\
\hline Rise time (s) & Lognormal & $f(x \mid a, b)=\frac{1}{x b \sqrt{2 \pi}} \exp \left[\frac{-(\ln x-a)^{2}}{2 b^{2}}\right]$ & $a=3.06, b=0.85$ \\
\hline Lapse time (s) & Lognormal & $f(x \mid a, b)=\frac{1}{x b \sqrt{2 \pi}} \exp \left[\frac{-(1 \mathrm{n} x-a)^{2}}{2 b^{2}}\right]$ & $a=3.27, b=0.84$ \\
\hline Gust asymmetric factor (unitless) & Lognormal & $f(x \mid a, b)=\frac{1}{x b \sqrt{2 \pi}} \exp \left[\frac{-(1 \mathrm{n} x-a)^{2}}{2 b^{2}}\right]$ & $\quad a=0.27, b=0.99$ \\
\hline Gust length scale (m) & Lognormal & $f(x \mid a, b)=\frac{1}{x b \sqrt{2 \pi}} \exp \left[\frac{-(1 \mathrm{n} x-a)^{2}}{2 b^{2}}\right]$ & $a=5.93, b=0.71$ \\
\hline
\end{tabular}

Table 2] have been used in a wide range of engineering applications [e.g., structural and fatigue analyses of WT blades (Hu et al. 2016; Jiang et al. 2015), dynamic and reliability analyses of tall buildings (Zhang et al. 2008), and simulation of long-span cable supported bridges $(\mathrm{Li}$ et al. 2017)]. The Kaimal spectral model has also recently been extended to include shear production of turbulence within the surface layer (Mikkelsen et al. 2017). Here these empirical spectral models are applied to derive estimates of the turbulence length scales and to investigate 1) whether the gust length scale is differentiable from the average turbulent length scale and 2) at what frequency range wind gusts contribute to variance in the power spectra.

The methodology applied to distinguish the gust length scales from the average turbulent length scale is as follows:

1) Calculate the empirical power spectral density (PSD) of the 10-Hz longitudinal wind speed in each 10-min period by detrending the time series and applying the Welch method to estimate the signal power at specific frequencies (Welch 1967). Apply the spectral models (Kaimal, von Kármán, new von Kármán, and Solari) to the empirical PSD and solve the equations shown in Table 2 for $L_{i}$.
2) Compare the gust length scale $L_{g}$ computed from Eq. (6) with the average turbulence length scales $L_{t}$ derived from Eq. (7) and those obtained by fitting the spectral models to the empirical PSD.

3) Evaluate the dependence of the length scales $\left(L_{i}, L_{t}\right.$, and $L_{g}$ ) on $U_{T}$ using least squares linear fitting.

4) Locate the frequency range associated with the presence of gusts in the turbulence spectrum. The gust period $\left(t_{g}=t_{r}+t_{l}\right)$ is identified in the normalized spectrum for each 10 -min period. The $99 \%$ confidence intervals of gust period $t_{g}$ are then located in the ensemble-averaged normalized spectra at both 3 and $65 \mathrm{~m}$ and compared with estimates from Mikkelsen's shear production subrange (SPS) model to study the relationship between shear production of turbulence and gust period.

\section{4) LINKING GUST CHARACTERISTICS TO LANDSCAPE PROPERTIES AND ATMOSPHERIC STABILITY}

Prior research and first-principle considerations indicate the importance of elevation variability, surface roughness, and land use patchiness in determining the dominant gust length scale and gust factors (Ashcroft 1994). As shown in Fig. 2 the topography and land use 
TABLE 2. Spectral models applied herein. Detailed derivations are given in the corresponding references.

\begin{tabular}{|c|c|}
\hline Spectrum name & Normalized spectrum \\
\hline $\begin{array}{l}\text { Kaimal spectrum (IEC 61400-1 Ed3) } \\
\text { (International Electrotechnical } \\
\text { Commission 2005) }\end{array}$ & $\begin{array}{l}\frac{f S_{i}(f)}{\sigma_{i}^{2}}=\frac{4 f L_{i} / V_{z}}{\left(1+6 f L_{i} / V_{z}\right)^{5 / 3}}, \quad i=u, v, w, \\
\text { where } f \text { is frequency }(\mathrm{Hz}) ; S_{i} \text { is power spectral density; } \sigma_{i} \text { is the standard deviation of wind } \\
\text { speed; } L_{i} \text { is the turbulence length scale; } V_{z} \text { is the mean wind speed at height } z \text {; and } u, v \text {, } \\
\text { and } w \text { represent longitudinal, transverse, and vertical wind components, respectively. }\end{array}$ \\
\hline $\begin{array}{l}\text { von Kármán spectrum } \\
\text { (Burton et al. 2011) }\end{array}$ & $\begin{array}{l}\frac{f S_{u}(f)}{\sigma_{u}^{2}}=\frac{4 f L_{u} / V_{z}}{\left[1+70.8\left(f L_{u} / V_{z}\right)^{2}\right]^{5 / 6}} \quad \text { and } \\
\frac{f S_{i}(f)}{\sigma_{i}^{2}}=\frac{4\left(f L_{i} / V_{z}\right)\left[1+755.2\left(f L_{i} / V_{z}\right)^{2}\right]}{\left[1+283.2\left(f L_{i} / V_{z}\right)^{2}\right]^{11 / 6}}, \quad i=v \text { and } w\end{array}$ \\
\hline $\begin{array}{l}\text { New von Kármán spectrum } \\
\text { (Engineering Sciences Data } \\
\text { Unit 2001) }\end{array}$ & $\begin{array}{l}\frac{f S_{u}(f)}{\sigma_{u}^{2}}=\beta_{1} \frac{2.987 n_{u} / \alpha}{\left[1+\left(2 \pi n_{u} / \alpha\right)^{2}\right]^{5 / 6}}+\beta_{2} \frac{1.294 n_{u} / \alpha}{\left[1+\left(\pi n_{u} / \alpha\right)^{2}\right]^{5 / 6}} F_{1}, \quad n_{u}=f L_{u} / V_{z} \\
\frac{f S_{i}(f)}{\sigma_{i}^{2}}=\beta_{1} \frac{2.987\left[1+(8 / 3)\left(4 \pi n_{i} / \alpha\right)^{2}\right]\left(n_{i} / \alpha\right)}{\left[1+\left(4 \pi n_{i} / \alpha\right)^{2}\right]^{11 / 6}}+\beta_{2} \frac{1.294 n_{i} / \alpha}{\left[1+\left(2 \pi n_{i} / \alpha\right)^{2}\right]^{5 / 6}} F_{2}, \quad n_{i}=f L_{i} / V_{z}, i=v \text { and } w, \\
\text { where derivations of coefficients } \alpha, \beta_{1}, \beta_{2}, F_{1} \text {, and } F_{2} \text { are as in Engineering Sciences Data } \\
\quad \text { Unit (2001). }\end{array}$ \\
\hline Solari spectrum (Solari 1993) & $\frac{f S_{i}(f)}{\sigma_{i}^{2}}=\frac{6.868 f L_{i} / V_{z}}{\left(1+10.32 f L_{i} / V_{z}\right)^{5 / 3}}, \quad i=u, v, w$ \\
\hline $\begin{array}{l}\text { SPS extended spectrum } \\
\quad \text { (Mikkelsen et al. 2017) }\end{array}$ & $\begin{array}{l}\frac{f S_{u}(f)}{\sigma_{u}^{2}}=\frac{\mu_{*}^{2}}{\sigma_{u}^{2}} \frac{a\left(f z / V_{z}\right) / f_{l}}{\left[1+\left(f z / V_{z}\right) / f_{l}\right]\left[1+\left(f z / V_{z}\right) / f_{u}\right]^{2 / 3}} \\
\text { where } \mu_{*} \text { is friction velocity; } f_{l} \text { and } f_{u} \text { are the lower bound and upper bound of the SPS, } \\
\quad \text { respectively. }\end{array}$ \\
\hline
\end{tabular}

around the meteorological mast exhibits notable directional variability. Thus, an analysis is undertaken to examine if the probability distributions of $L_{g}$ and $G_{t, T}$ differ according to wind direction, where the data are conditionally sampled into four sectors: east $\left(45^{\circ} \leq D<\right.$ $\left.135^{\circ}\right)$, south $\left(135^{\circ} \leq D<225^{\circ}\right)$, west $\left(225^{\circ} \leq D<315^{\circ}\right)$, and north $\left(315^{\circ} \leq D \leq 360^{\circ}\right.$ or $\left.0^{\circ} \leq D<45^{\circ}\right)$.

To further quantify the relationships between gust parameters and landscape properties, $L_{g}$ and $G_{t, T}$ are also conditionally sampled along sixteen $22.5^{\circ}$ sectors extending from the mast based on both a new proposed descriptor of terrain variability [terrain peak wavelength (TPW)] and surface roughness parameter $K_{r}$ introduced by Ashcroft (1994):

$$
K_{r}=2.5855 \frac{\ln \left[(z-d) / z_{0}\right]}{\ln \left(10^{5 / z_{0}}\right)}
$$

where $z$ is the measurement height. Here, $K_{r}$ is computed based on the land cover data along a 3000-m transect beginning at the mast where $z_{0}$ is the log-averaged surface roughness length for the sector [derived based on the LANDFIRE land cover classes using approximations from Pineda et al. (2004)], and $d$ is the mean zero-plane displacement associated with each sector [estimated as $2 / 3$ of the vegetation height (Oke 1987) as described for each class in the LANDFIRE data].
TPW is a proposed new metric of terrain complexity and length scales. It is computed for each directional sector as a weighted average of spatial-domain fast Fourier transform (FFT) of elevation along a 12.8-km radial transect. Each of the 16 directional transects is partitioned into eight $1600-\mathrm{m}$ subtransects, and the FFT for each subtransect is taken. Each direction sector is represented by a weighted average of the 8 FFTs with the $i$ th FFT given a weight of $1 / 2^{(i-1)}$, giving much more weight to terrain characteristics close to the mast than those farther away. The TPW is defined as the wavelength associated with the peak variance in each of these weighted-average FFTs for the sector. It thus represents the dominant length scale of elevation variability along the sectoral transect. Relationships between the median gust parameters (gust length scale and gust factor) and TPW and $K_{r}$ in each sector are quantified using least squares linear fitting.

To evaluate the dependence of gust characteristics on atmospheric stability the Monin-Obukhov length (Monin and Obukhov 1954) is computed for each 10-min period using

$$
L=-\frac{u_{*}^{3} T_{0}}{\kappa g \overline{w^{\prime} T_{0}^{\prime}}},
$$

where $u_{*}=\sqrt{\left|\overline{u^{\prime} w^{\prime}}\right|}$ is the friction velocity, $T_{0}$ is the absolute temperature, $\kappa \approx 0.4$ is the von Kármán 
constant, $g \approx 9.81 \mathrm{~m} \mathrm{~s}^{-2}$ is gravitational acceleration, and $u^{\prime}, w^{\prime}$, and $T_{0}^{\prime}$ are the fluctuations of $u, w$, and $T_{0}$, respectively. Then gust characteristics $\left(L_{g}\right.$ and $\left.G_{t, T}\right)$ are conditionally sampled in seven stability classes (see Table 3). The probability gust values above certain threshold are evaluated using

$$
\begin{aligned}
P\left(L_{g}>x\right) & =1-\Phi_{L}(x) \quad \text { and } \\
P\left(G_{t, T}>x\right) & =1-\Phi_{G}(x)
\end{aligned}
$$

where $\Phi_{L}$ and $\Phi_{G}$ are the cumulative distribution function $(\mathrm{CDF})$ of $L_{g}$ and $G_{t, T}$ respectively, derived using the best-fit distributions to these parameters.

\section{Results and discussion}

Section 4 provides results and discussion of distributional fits to gust parameters, gust parameterizations, gust signatures in turbulence spectra, and gust characteristics linked to landscape properties and atmospheric stability.

\section{a. Distributional fits to gust parameters}

Figure 5 and Table 1 summarize the distributional fits for the 10 gust parameters. Based on the criteria of the maximum log-likelihood estimate it is found that the lognormal distribution and the Weibull distribution are best fit for the peak gust and the gust amplitude, respectively (Figs. 5a,b), while $G_{t, T}$ and $k_{t, T}$ most closely conform to the log-logistic distribution (Figs. 5c,d). Optimal distributions for these parameters thus differ from the distributions used to represent $G_{t, T}$ and $k_{t, T}$ in some previous research [e.g., lognormal distribution used for $G_{t, T}$ (Jungo et al. 2002) and Gumbel distribution used for $k_{t, T}$ (Bardal and Sætran 2016)] and has implications for extrapolation to the tails of these distributions. The lognormal distribution is the best fit for the gust length scale (Fig. 5j). Although the Weibull distribution is frequently applied to describe the wind speed distribution, it is obvious from Fig. 5 that it is not a good fit for either the gust factor or the peak factor.

The rise and lapse magnitudes are best fit by the Weibull and gamma distributions, respectively, although given that the increase in $\log \mathrm{L}$ for the gamma distribution is very minor for the lapse magnitude, it may be convenient to use the Weibull distribution to describe both the rise and lapse magnitudes (Figs. 5e,f). The mean rise time and mean lapse time are found to be 31.4 and $37.5 \mathrm{~s}$ respectively, which implies that the average gust period $(>1 \mathrm{~min})$ is much longer than the extreme operating gust case for WT loading suggested by IEC (International Electrotechnical Commission 2005).
TABLE 3. Atmospheric stability classes based on the Monin-Obukhov length $L$ as defined in Suomi et al. (2013).

\begin{tabular}{lc}
\hline \hline Atmospheric stability class & $\begin{array}{c}\text { Monin-Obukhov } \\
\text { length interval (m) }\end{array}$ \\
\hline Very stable (vs) & $10<L<50$ \\
Stable (s) & $50<L<200$ \\
Near-neutral stable (ns) & $200<L<500$ \\
Neutral (n) & $|L|>500$ \\
Near-neutral unstable (nu) & $-500<L<-200$ \\
Unstable (u) & $-200<L<-100$ \\
Very unstable (vu) & $-100<L<-50$ \\
\hline
\end{tabular}

The lognormal distribution is the best fit for both the rise time and lapse time of gusts (Figs. 5g,h). The best distributional fits to rise and lapse time implied by this analysis for a site in moderately complex terrain typical of the northeastern United States thus also differ from those (Weibull) applied to data from coastal site off the west coast of Norway (Bardal and Sætran 2016). The distribution of the rise time derived from our measurements at $65 \mathrm{~m}$ is substantially more right-skewed than that of the lapse time. Hence, the gust asymmetry parameter is also strongly right-skewed (Fig. 5i) and is best fitted by the lognormal distribution. This indicates a substantial deviation from the symmetric Mexican-hat form and may result in different dynamic responses of WT systems under high loading. Further, evidence that the gust events have larger rise acceleration than lapse deceleration may have implications for reliable power control at high gusts (Branlard 2009).

\section{b. Gust parameterizations}

Peak factor $k_{t, T}$ values from the $65-\mathrm{m}$ sonic data do not exhibit a very strong linear dependence on $U_{T}$ or $I_{T}$. Indeed the slopes in the linear fits are slightly negative (Figs. 6c,d). Conversely, consistent with prior research, the gust factor $G_{t, T}$ exhibits a strong dependence on $I_{T}$ (slope coefficient of 2.21 and intercept of 1 for $I_{T}$ values of $0-1$ ) and a (very weak) positive dependence on $U_{T}$ (Durst 1960; Figs. 6a,b). Thus, although prior research has proposed predictive models for wind gusts based on the conditional probability of a gust factor for given value of mean wind speed (Thorarinsdottir and Johnson 2012), at least at this site when considering the entire data sample, there is only a weak dependence of the gust factor on $U_{T}$. Similarly, although the intercept (2.36) of the linear fits of $k_{t, T}$ as a function of $U_{T}$ is close to the constant peak factor $(\sim 2.2)$ obtained by (Bardal and Sætran 2016), the dependence of the peak factor on $U_{T}$ is also weak.

The best-fit function linking $G_{t, T}$ to $I_{T}$ as derived from our data exhibits a weaker dependence on $I_{T}$ than the models of Greenway [Eq. (9)], Deaves and Harris [Eq. (10)], and Bardal and Sætran [Eq. (12)]. Indeed, even 

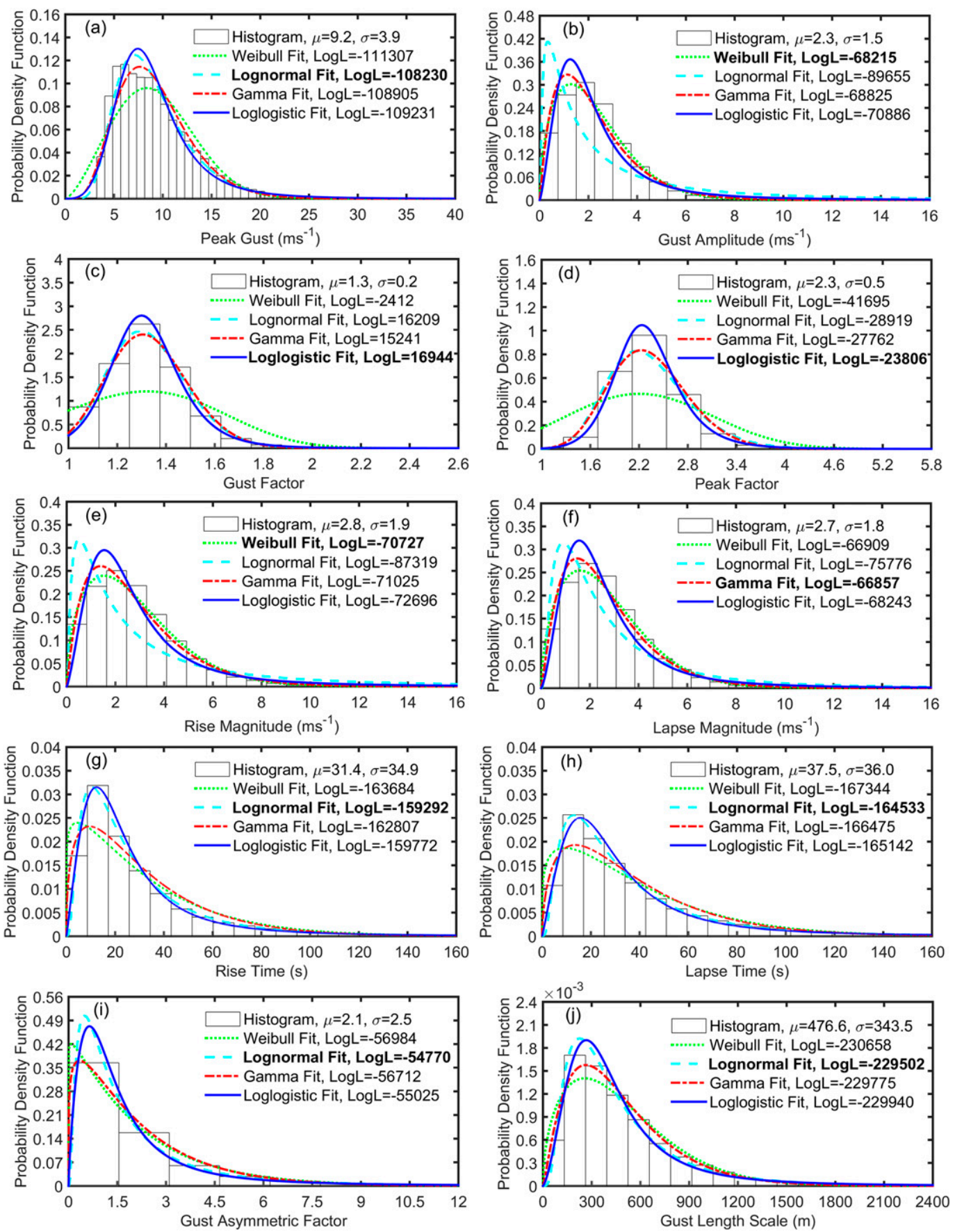

FIG. 5. Histograms of the observational data and distribution fits for the 10 gust parameters: (a) peak gust, (b) gust amplitude, (c) gust factor, (d) peak factor, (e) rise magnitude, (f) lapse magnitude, (g) rise time, (h) lapse time, (i) gust asymmetric factor, and (j) gust length scale. Recall the data have been conditionally sampled to select only period when $U_{T} \geq 3 \mathrm{~ms}^{-1}$. Four positive-valued distribution types, Weibull, lognormal, gamma, and log-logistic, are used in the distribution fitting. In the legends, $\mu=$ mean, $\sigma=$ standard deviation, and $\log \mathrm{L}=\log$-likelihood value. The bolded distribution with the largest $\log \mathrm{L}$ is selected as the best-fit distribution and is summarized in Table 1.

though those models were obtained in a manner similar to that used herein, they are conservative for estimating $G_{t, T}$ for the range of $I_{T}$ considered here and particularly in the range of $0.2-0.3$ (Fig. $6 \mathrm{~b}$ ). At $I_{T}>0.3$, the extrapolated $G_{t, T}$ values (dashed red, magenta, and cyan lines in Fig. 6b) based on those models exhibit even greater discrepancy with the results from the current study. 

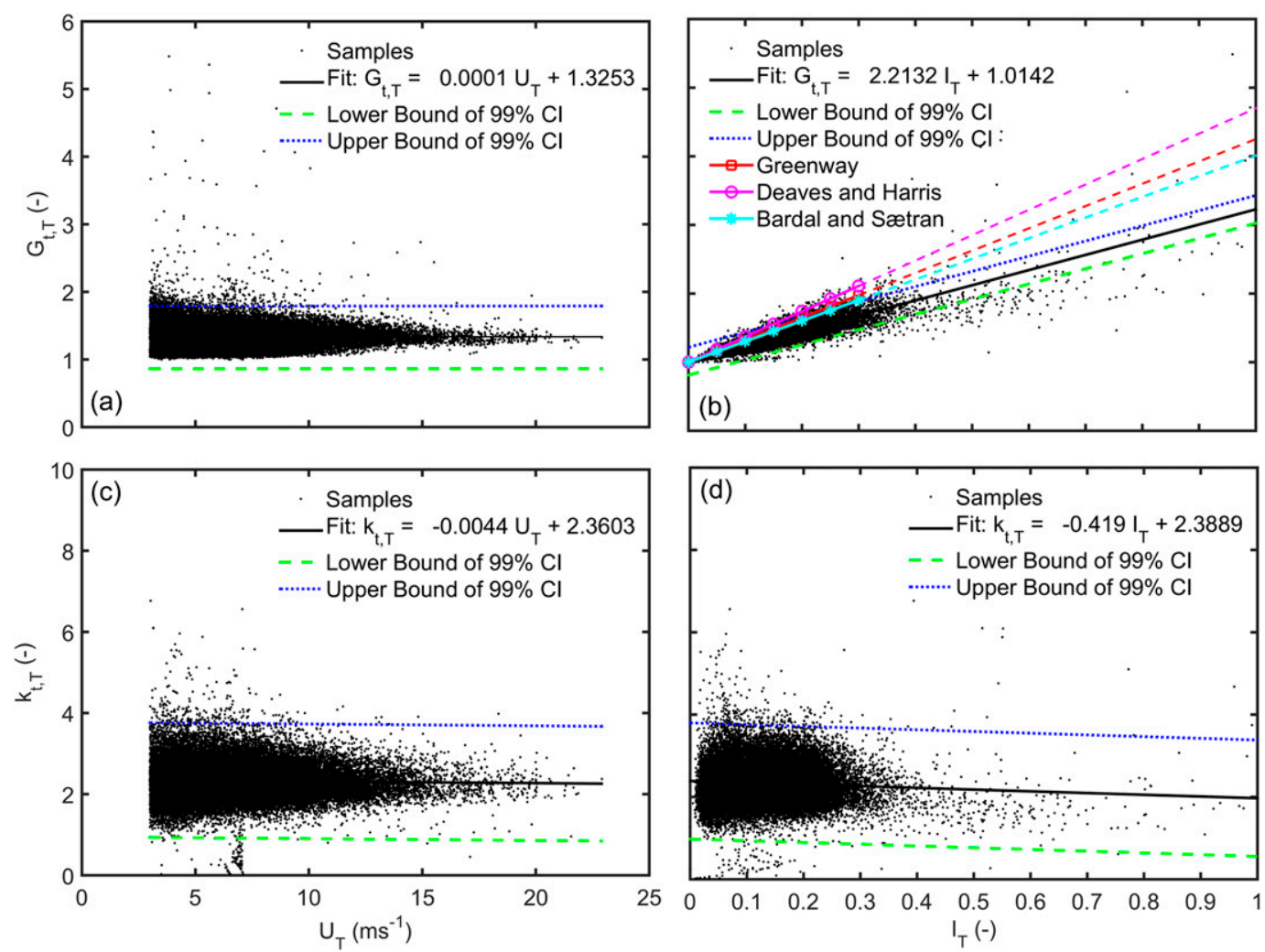

FIG. 6. Scatterplots of, and linear regression fits to, the (a) gust factor $G_{t, T}$ vs 10-min mean wind speed $U_{T}$, (b) gust factor $G_{t, T}$ vs 10-min turbulence intensity $I_{T}$, (c) peak factor $k_{t, T}$ vs 10-min mean wind speed $U_{T}$, and (d) peak factor $k_{t, T}$ vs 10-min turbulence intensity $I_{T}$. In (b) the empirical models of Greenway (1979), Deaves and Harris (1976), and Bardal and Sætran (2016) are also shown. Note that gust factors from the three models have been extrapolated from the range of $I_{T}$ on which they were conditioned to cover the entire range of observed $I_{T}$ values. Data are only shown for periods when $U_{T}$ at $65 \mathrm{~m} \geq 3 \mathrm{~m} \mathrm{~s}^{-1}$.

\section{c. Gust signatures in turbulence spectra}

Although characteristic turbulent length scales depend on $z_{0}$ and measurement height, they are typically reported to be of the order of $100 \mathrm{~m}$ (Burton et al. 2011). Consistent with that, the mean turbulent length scales $L_{t}$ at $65 \mathrm{~m}$ from Eq. (7) and four spectral models ( $L_{\text {kaim}}$, $\left.L_{\mathrm{vkar}}, L_{\mathrm{nvakr}}, L_{\mathrm{sol}}\right)$ are $95-192 \mathrm{~m}$. Further, consistent with prior research (Li et al. 2010), both the gust and turbulence length scales increase with height and wind speed (Figs. 7a,b). The turbulent length scale increases approximately linearly with $U_{T}$ at both 65 and $3 \mathrm{~m}$ (Figs. 7a,b), as does $L_{g}$ derived from Eq. (6). However, $L_{g}$ exhibits consistently larger values as a function of $U_{T}$ and exhibits a greater sensitivity to changing $U_{T}$. The prefactor coefficients in the least squares linear fits of $L_{g}$ to $U_{T}$ are 5-10 times higher than those for the turbulent length scale (Figs. 7a,b). In addition, the interquartile ranges (IQR) of $L_{g}$ and $L_{t}$ are separated at both 3 and $65 \mathrm{~m}$ (Figs. 7a,b). Thus gusts have characteristic sizes that are typically larger than the mean turbulent eddy length, and gusts with larger $L_{g}$ are more likely to be observed at high sustained wind speeds and greater heights in the surface layer.

Figures $7 \mathrm{c}$ and $7 \mathrm{~d}$ provide ensemble-averaged normalized empirical spectra based on measurements at $3 \mathrm{~m}$ and $65 \mathrm{~m}$, respectively, along with those derived from a spectral model including shear production of turbulence. The $99 \%$ confidence interval of the normalized gust period (i.e., $t_{g}=t_{r}+t_{l}$, expressed as a frequency and normalized by height and the mean sustained wind speed) lies entirely within the SPS at $3 \mathrm{~m}$ (Fig. 7c), whereas it exhibits only partial overlap with the SPS in data collected at $65 \mathrm{~m}$ (Fig. 7d). This finding implies that coherent wind gusts at $3 \mathrm{~m}$ are constrained and/or affected by vertical shear close to the ground, while as the height increases, gusts are likely to be affected and/or dominated by other phenomena (e.g., fetch and stability).

\section{d. Linking gust characteristics to landscape properties and atmospheric stability}

The probability distributions of gust length scale and gust factor at $65 \mathrm{~m}$ for northerly flow exhibit 

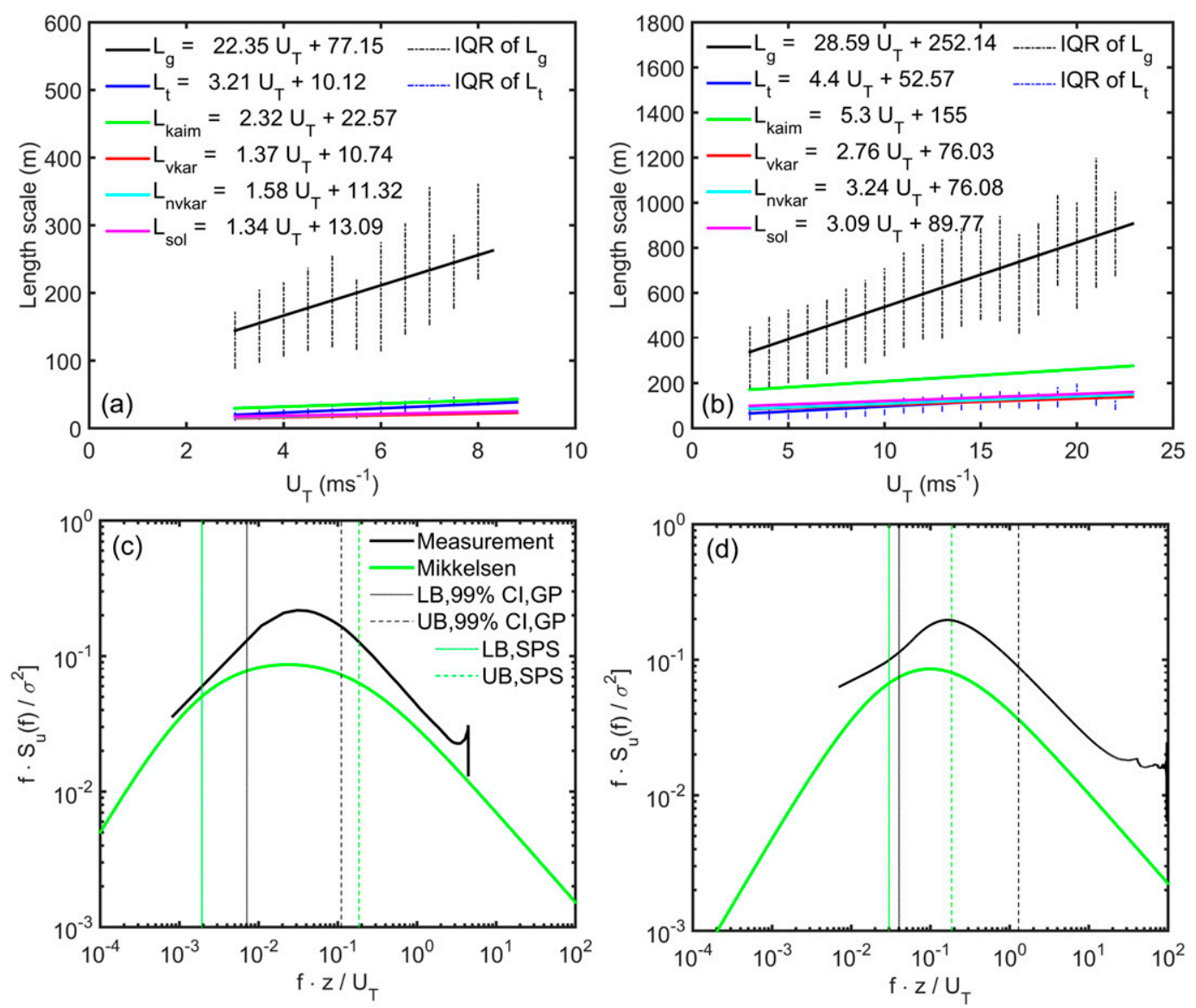

FIG. 7. Least squares linear fits of gust length scale and turbulence length scales conditionally sampled by 10-min longitudinal mean wind speed at (a) 3 and (b) $65 \mathrm{~m}$. IQRs of $L_{g}$ (black dash-dotted lines) and $L_{t}$ (blue dash-dotted lines) in binned wind speeds are also shown in (a) and (b). Also shown are the ensemble-averaged spectrum (black curve) based on measured longitudinal wind speed at (c) 3 and (d) $65 \mathrm{~m}$, along with the $99 \%$ CIs of the gust period (GP) and the peak in Mikkelsen's SPS extended spectrum model (green curves) with the SPS's lower bound (LB) and upper bound (UB).

considerably higher median and modal values and stronger positive skewness than in other wind directions (Figs. 8a,b). Given the variability in terrain and land cover (Figs. 2c,d), this is symptomatic of a possible landscape effect in determining gust structures. Hence, the median gust length scales and gust factors for each of the 16 radial transects were evaluated relative to the transect TPW and $K_{r}$ (see examples for $6.5 \leq U_{T} \leq$ $7.5 \mathrm{~m} \mathrm{~s}^{-1}$ shown in Figs. 8c-f). Although the gust ratio median values $(\sim 1.3)$ are consistent with previously reported values for a $K_{r}$ of $\sim 1.1$ (Ashcroft 1994) and both gust parameters appear to exhibit a positive dependence on both TPW and $K_{r}$ (as manifest in the regression slope coefficients), the relationships are subject to considerable scatter. The lack of a strong dependence on these parameters may reflect the relatively small range of $K_{r}$ and TPW values sampled along our transects [cf. $K_{r}$ values reported in Ashcroft (1994) that range from 0.5 to 1.3] or the relatively coarse resolution of the SRTM and LANDFIRE data. These results also imply that the directional variability of gust properties may be more strongly influenced by upstream effects not characterized in TPW and/or $K_{r}$ or other factors such as stability variations by directional sector.

As shown in Figs. 9a and 9b, there is a significantly higher probability for large values of both the gust length scale and gust factor under unstable conditions [i.e., very unstable (vu), unstable (u), and near-neutral unstable (nu)] than in stable conditions [i.e., very stable (vs) and stable (s)]. The relatively high frequency of unstable conditions under northerly flow (Fig. 9c) is thus a contributory (and possibly dominant) factor in causing the high probability of large $L_{g}$ and $G_{t, T}$ in this sector (Figs. 8a,b). 
(a)

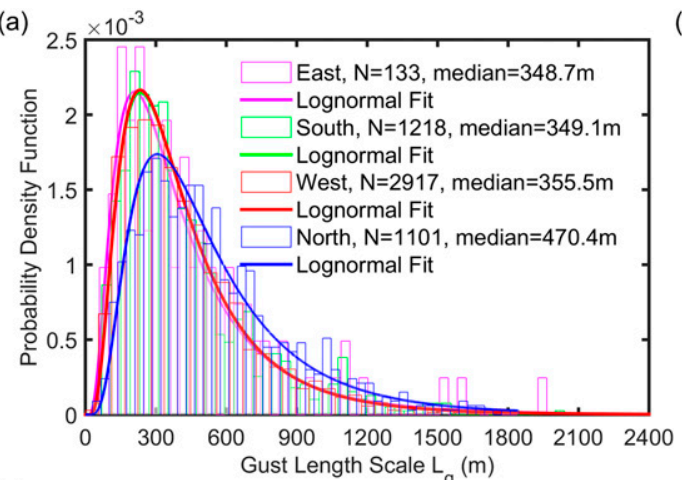

(b)

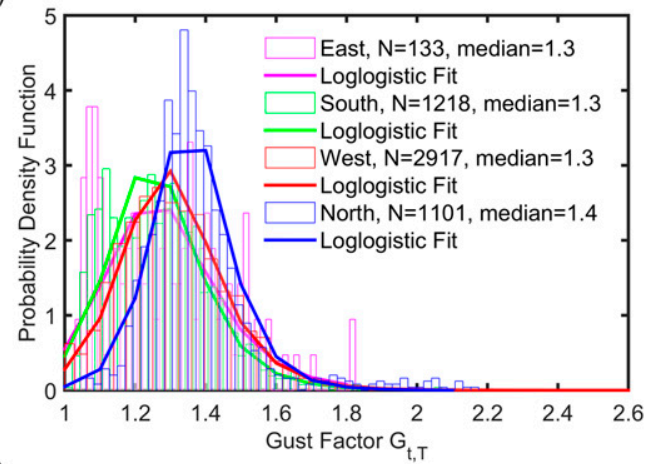

(d)
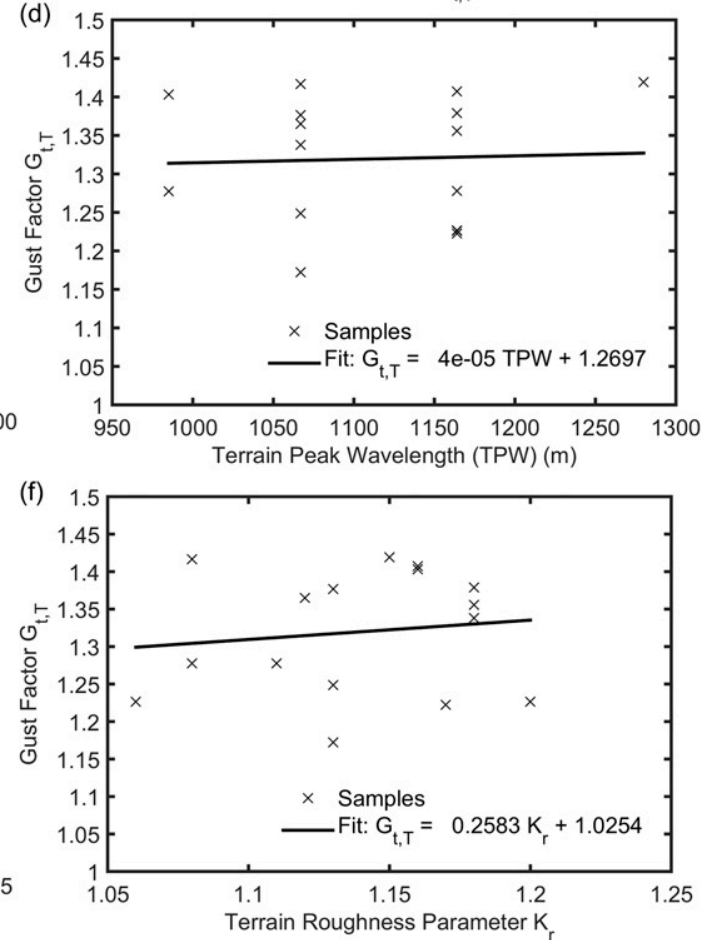

FIG. 8. An example of the probability distributions and functional dependencies of $L_{g}$ and $G_{t, T}$ for all 10-min periods with $6.5 \leq U_{T} \leq 7.5 \mathrm{~m} \mathrm{~s}^{-1}$ at $65 \mathrm{~m}$. (a) Lognormal distribution fit for gust length scales $L_{g}$ and (b) log-logistic distribution fit for gust factors $G_{t, T}$ (at $65 \mathrm{~m}$ ) conditionally sampled into four directional $D$ sectors; east $\left(45^{\circ} \leq D<\right.$ $\left.135^{\circ}\right)$, south $\left(135^{\circ} \leq D<225^{\circ}\right)$, west $\left(225^{\circ} \leq D<315^{\circ}\right)$, and north $\left(315^{\circ} \leq D \leq 360^{\circ}\right.$ or $\left.0^{\circ} \leq D<45^{\circ}\right)$. Also shown are the sector median (c) $L_{g}$ vs TPW, (d) $G_{t, T}$ vs TPW, (e) $L_{g}$ vs terrain roughness parameter $K_{r}$, and (f) $G_{t, T}$ vs $K_{r}$.

\section{Concluding remarks}

More accurate descriptions of wind gust characteristics are needed for a number of applications. It is also important to evaluate the degree to which it is possible to deconvolute wind fluctuations into the contributions from coherent (wind gust) and incoherent (turbulent fluctuations) components and to characterize their respective time and length scales when predicting possible structural dynamic responses. This paper presents a comprehensive study of gust characteristics at WT relevant heights based on high-resolution wind measurements at a site in moderately complex terrain. The key findings are the following:

- The probability distributions that most accurately represent the 10 descriptors of wind gusts reflect the drivers of those parameters (e.g., anisotropy of the flow components contributing to the gust) and can be grouped into three classes:

1) Lognormal distributions are most appropriate for rise time, lapse time, GAF, peak gust, and gust length scale.

2) The Weibull distribution is most appropriate for gust amplitude, rise magnitude, and lapse magnitude. 

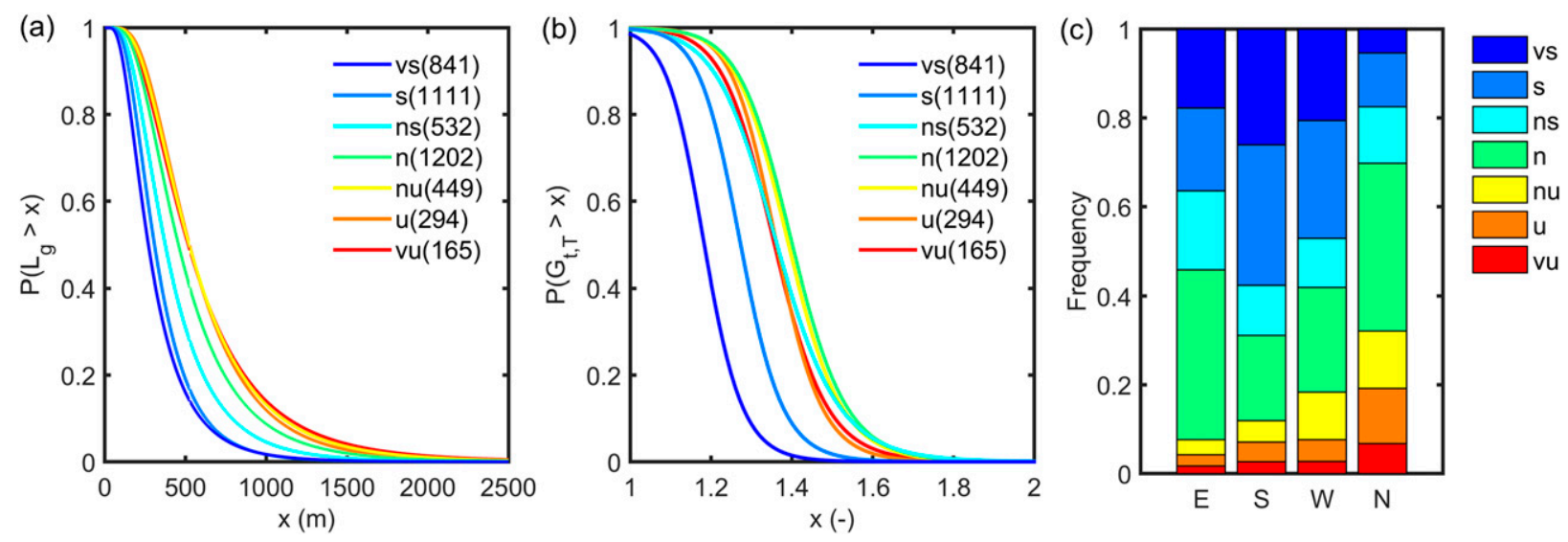

FIG. 9. Probability of (a) gust length scale and (b) gust factor larger than a specified value conditionally sampled by Monin-Obukhov length $L$ (see Table 3 for the class definitions) for all periods when $6.5 \leq U_{T} \leq 7.5 \mathrm{~m} \mathrm{~s}^{-1}$ at $65 \mathrm{~m}$. The total number of 10 -min periods is given inside the parentheses after the abbreviation of stability classes in the legend. Lognormal distribution and loglogistic distribution are used to fit the gust length scales and gust factors, respectively, to calculate the CDF. (c) Frequency of the seven stability classes in the four directional sectors: east $(\mathrm{E})$, south $(\mathrm{S})$, west $(\mathrm{W})$, and north $(\mathrm{N})$.

3) The log-logistic distribution is a best fit for the gust factor and peak factor.

- Gust factors increase linearly with turbulence intensity, but previous models tend to overpredict, and are thus conservative, in terms of predicted $G_{t, T}$ for given $I_{T}$.

- The time evolution of wind gusts is highly asymmetric and differs substantially from the Mexican-hat form invoked in WT loading cases.

- Gust length scales are generally longer than the mean turbulence length scales and increase more rapidly with increasing $U_{T}$.

- There is a clear dependence of gust length scale and gust factor on wind direction. At this site, larger gust length scales are associated with northerly flow. While this is a partially a result of terrain and land cover features (as characterized using $K_{r}$ and a new descriptor of terrain length scales, TPW), the directional bias appears to be more strongly related to a higher frequency of unstable conditions under northerly flow.

Naturally, at least some of these findings may be site specific, and there is a need for further work to assess their generalizability both in times of the regional climate (i.e., in the context of climatological variability) and in space (i.e., at other sites). However if generalizable, then the results presented herein may have great utility in efforts to reformulate aerodynamic loading cases for the wind turbine design standards and may afford opportunities for statistical forecasting of wind gust occurrence and climatologies.

Acknowledgments. We gratefully acknowledge funding from the U.S. National Science Foundation (1540393 and 1565505), the Cornell University David R. Atkinson Center for a Sustainable Future (ACSF), and the U.S. Department of Energy (DE-SC0016438).

\section{APPENDIX}

\section{List of Parameters and Definitions (Including Mathematical Derivation and Unit)}

ACF Autocorrelation function

$A_{D} \quad$ WT drivetrain acceleration $\left(\mathrm{m} \mathrm{s}^{-2}\right)$

$A_{T} \quad$ WT tower acceleration $\left(\mathrm{m} \mathrm{s}^{-2}\right)$

CDF Cumulative distribution function

D $\quad$ 10-min mean wind direction $\left({ }^{\circ}\right)$

$d \quad$ Mean zero-plane displacement (m)

FFT Fast Fourier transform

GAF Gust asymmetric factor, GAF $=\left(u_{r} / t_{r}\right) /\left(u_{l} / t_{l}\right)$

$G_{t, T} \quad$ Gust factor, i.e., $G_{t, T}=u_{t, T}^{\max } / U_{T}$

$g \quad$ Gravitational acceleration $\left(\mathrm{m} \mathrm{s}^{-2}\right)$

$I_{T} \quad 10$-min turbulence intensity, i.e., $I_{T}=\sigma_{T} / U_{T}$

$K_{r} \quad$ Surface roughness parameter introduced by

Ashcroft (1994)

$k_{t, T} \quad$ Peak factor, i.e., $k_{t, T}=u_{t, T}^{a} / \sigma_{T}$

$L \quad$ Monin-Obukhov length (m)

$L_{g} \quad$ Gust length scale, i.e., $L_{g}=\int_{t_{\mathrm{vv}}}^{t_{\mathrm{ev}}} u_{t, T}(t) d t(\mathrm{~m})$

$L_{t} \quad$ Integral length scale, i.e., $L_{t}=U_{T} \int_{0}^{\infty} \operatorname{ACF}(\tau) d \tau(\mathrm{m})$

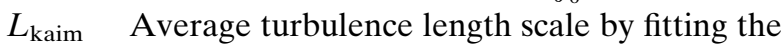

Kaimal spectrum to empirical PSD (m)

$L_{\mathrm{vkar}} \quad$ Average turbulence length scale by fitting the von Kármán spectrum to empirical PSD (m) 


\begin{tabular}{|c|c|c|}
\hline$L_{\text {nvkar }}$ & $\begin{array}{l}\text { Average turbulence length scale by fitting the } \\
\text { new von Kármán spectrum to empirical } \\
\text { PSD (m) }\end{array}$ & $\begin{array}{l}w^{\prime} \\
w_{t, T}\end{array}$ \\
\hline$L_{\mathrm{sol}}$ & $\begin{array}{l}\text { Average turbulence length scale by fitting the } \\
\text { Solari spectrum to empirical PSD }(\mathrm{m})\end{array}$ & $w_{t}, T \mathrm{gp}$ \\
\hline PSD & Power spectral density & \\
\hline TPW & Terrain peak wavelength $(\mathrm{m})$ & $z$ \\
\hline$T$ & Sampling period, $T=10 \mathrm{~min}$ & $z_{0}$ \\
\hline$T_{0}$ & Absolute temperature $(\mathrm{K})$ & $\sigma_{T}$ \\
\hline$T_{0}^{\prime}$ & Fluctuation of absolute temperature $(\mathrm{K})$ & $\kappa$ \\
\hline$t$ & Moving-average time window, $t=3 \mathrm{~s}$ & $\Phi_{L}$ \\
\hline$t_{\mathrm{ev}}$ & UTC time at the end-valley of a gust event & $\Phi_{G}$ \\
\hline$t_{g}$ & Gust period, i.e., $t_{g}=t_{r}+t_{l}(\mathrm{~s})$ & \\
\hline$t_{l}$ & Gust lapse time, i.e., $t_{l}=t_{\mathrm{ev}}-t_{\mathrm{max}, t}(\mathrm{~s})$ & \\
\hline$t_{\max , t}$ & UTC time at the peak of a gust event & \\
\hline
\end{tabular}

Fluctuation of vertical raw wind speed $\left(\mathrm{m} \mathrm{s}^{-1}\right)$ 3-s moving average vertical wind speed during a 10 -min period $\left(\mathrm{m} \mathrm{s}^{-1}\right)$

3-s mean vertical wind speed at the time moment of a gust peak in longitudinal direction $\left(\mathrm{m} \mathrm{s}^{-1}\right)$

Height (m) Surface roughness $(\mathrm{m})$

10-min standard deviation of wind speed $\left(\mathrm{m} \mathrm{s}^{-1}\right)$

Cumulative distribution function of $L_{g}$ Cumulative distribution function of $G_{t, T}$

Ágústsson, H., and H. Ólafsson, 2004: Mean gust factors in complex terrain. Meteor. Z., 13, 149-155, https://doi.org/10.1127/ 0941-2948/2004/0013-0149.

ASCE, 2010: Minimum Design Loads for Buildings and Other Structures. American Society of Civil Engineers, 608 pp.

Ashcroft, J., 1994: The relationship between the gust ratio, terrain roughness, gust duration and the hourly mean wind speed. J. Wind Eng. Ind. Aerodyn., 53, 331-355, https://doi.org/ 10.1016/0167-6105(94)90090-6.

Bardal, L. M., and L. R. Sætran, 2016: Wind gust factors in a coastal wind climate. Energy Procedia, 94, 417-424, https://doi.org/ 10.1016/j.egypro.2016.09.207.

Beljaars, A. C. M., 1987: The influence of sampling and filtering on measured wind gusts. J. Atmos. Oceanic Technol., 4, 613-626, https://doi.org/10.1175/1520-0426(1987)004<0613: TIOSAF $>2.0 . \mathrm{CO} ; 2$.

Bierbooms, W., 2005: Constrained stochastic simulation-Generation of time series around some specific event in a normal process. Extremes, 8, 207-224, https://doi.org/10.1007/s10687-006-7968-7.

— calculations of wind turbines. J. Wind Eng. Ind. Aerodyn., 90, 1237-1251, https://doi.org/10.1016/S0167-6105(02)00255-6.

Boettcher, F., C. Renner, H.-P. Waldl, and J. Peinke, 2003: On the statistics of wind gusts. Bound.-Layer Meteor., 108, 163-173, https://doi.org/10.1023/A:1023009722736.

Branlard, E., 2009: Wind energy: On the statistics of gusts and their propagation through a wind farm. ECN Wind Memo. 09-005, $48 \mathrm{pp}$.

$V_{T} \quad 10$-min mean wind speed in transverse direction $\left(\mathrm{m} \mathrm{s}^{-1}\right)$

$v \quad$ Transverse raw wind speed in $10 \mathrm{~Hz}\left(\mathrm{~m} \mathrm{~s}^{-1}\right)$

$v^{\prime} \quad$ Fluctuation of transverse raw wind speed $\left(\mathrm{m} \mathrm{s}^{-1}\right)$

$v_{t, T} \quad 3$-s moving average transverse wind speed during a $10-\min$ period $\left(\mathrm{m} \mathrm{s}^{-1}\right)$

$v_{t, T \mid \mathrm{gp}} \quad 3$-s mean transverse wind speed at the time moment of a gust peak in longitudinal direction $\left(\mathrm{m} \mathrm{s}^{-1}\right)$

$W_{T} \quad 10$-min mean wind speed in vertical direction $\left(\mathrm{m} \mathrm{s}^{-1}\right)$

$w \quad$ Vertical raw wind speed in $10 \mathrm{~Hz}\left(\mathrm{~m} \mathrm{~s}^{-1}\right)$

Brasseur, O., 2001: Development and application of a physical approach to estimating wind gusts. Mon. Wea. Rev., 129, 5-25, https://doi.org/ 10.1175/1520-0493(2001)129<0005:DAAOAP>2.0.CO;2.

Burton, T., N. Jenkins, D. Sharpe, and E. Bossanyi, 2011: Wind Energy Handbook. 2nd ed. John Wiley and Sons, 780 pp.

Camp, T. R., and H.-W. Shin, 1995: Turbulence intensity and length scale measurements in multistage compressors. J. Turbomach., 117, 38-46, https://doi.org/10.1115/1.2835642.

Chan, P. W., 2012: An event of tail strike of an aircraft due to terrain-induced wind shear at the Hong Kong International Airport. Meteor. Appl., 19, 325-333, https://doi.org/10.1002/ met.264.

Cheng, P. W., and W. Bierbooms, 2001: Distribution of extreme gust loads of wind turbines. J. Wind Eng. Ind. Aerodyn., 89, 309-324, https://doi.org/10.1016/S0167-6105(00)00084-2. 
Danish Society of Engineers, 1992: DS 472: Code of practice for loads and safety of wind turbine constructions. Danish Society of Engineers and the Federation of Engineers Tech. Rep., 78 pp.

Deaves, D. M., and R. I. Harris, 1976: A mathematical model of the structure of strong winds. Environmental Sciences Research Unit Rep. 24, 49 pp.

Dimitrov, N., 2016: Comparative analysis of methods for modelling the short-term probability distribution of extreme wind turbine loads. Wind Energy, 19, 717-737, https://doi.org/10.1002/ we.1861.

Dupont, S., D. Pivato, and Y. Brunet, 2015: Wind damage propagation in forests. Agric. For. Meteor., 214-215, 243-251, https://doi.org/10.1016/j.agrformet.2015.07.010.

Durst, C. S., 1960: Wind speeds over short periods of time. Meteor. Mag., 89, 181-186.

Engineering Sciences Data Unit, 2001: Characteristics of atmospheric turbulence near the ground. Part II: Single point data for strong winds (neutral atmosphere). ESDU Tech. Rep. $85020,37 \mathrm{pp}$.

Farr, T. G., and Coauthors, 2007: The Shuttle Radar Topography Mission. Rev. Geophys., 45, RG2004, https://doi.org/10.1029/ 2005RG000183.

Frost, W., and R. E. Turner, 1982: A discrete gust model for use in the design of wind energy conversion systems. J. Appl. Meteor., 21, 770-776, https://doi.org/10.1175/1520-0450(1982)021<0770: ADGMFU $>2.0 . \mathrm{CO} ; 2$.

Germanischer Lloyd, 2010: Guideline for the certification of wind turbines. Germanischer Lloyd Industrial Services Tech. Rep., 389 pp.

Greenway, M. E., 1979: An analytical approach to wind velocity gust factors. J. Wind Eng. Ind. Aerodyn., 5, 61-91, https:// doi.org/10.1016/0167-6105(79)90025-4.

Hogg, R. V., A. T. Craig, and J. W. McKean, 2005: Introduction to Mathematical Statistics. 6th ed. Pearson Prentice Hall, 704 pp.

Holmes, J. D., A. C. Allsop, and J. D. Ginger, 2014: Gust durations, gust factors and gust response factors in wind codes and standards. Wind Struct., 19, 339-352, https://doi.org/10.12989/ was.2014.19.3.339.

Hu, W., D. Park, and D. Choi, 2013: Structural optimization procedure of a composite wind turbine blade for reducing both material cost and blade weight. Eng. Optim., 45, 1469-1487, https://doi.org/10.1080/0305215X.2012.743533.

—, K. K. Choi, O. Zhupanska, and J. H. J. Buchholz, 2016: Integrating variable wind load, aerodynamic, and structural analyses towards accurate fatigue life prediction in composite wind turbine blades. Struct. Multidiscip. Optim., 53, 375-394, https://doi.org/10.1007/s00158-015-1338-5.

_ S. C. Pryor, F. Letson, J. Tytell, and R. J. Barthelmie, 2017: Investigation of gust-seismic relationships and applications to gust detection. J. Geophys. Res. Atmos., 122, 140-151, https:// doi.org/10.1002/2016JD025858.

International Electrotechnical Commission, 2005: Wind turbinesPart I: Design requirements. IEC Rep. 61400-1, 90 pp.

Jiang, Z., Y. Xing, Y. Guo, T. Moan, and Z. Gao, 2015: Long-term contact fatigue analysis of a planetary bearing in a land-based wind turbine drivetrain. Wind Energy, 18, 591-611, https:// doi.org/10.1002/we.1713.

Jungo, P., S. Goyette, and M. Beniston, 2002: Daily wind gust speed probabilities over Switzerland according to three types of synoptic circulation. Int. J. Climatol., 22, 485-499, https:// doi.org/10.1002/joc.741.

Kwon, D.-K., and A. Kareem, 2009: Gust-front factor: New framework for wind load effects on structures. J. Struct. Eng.,
135, 717-732, https://doi.org/10.1061/(ASCE)0733-9445(2009) 135:6(717)

Larsen, G. C., and K. S. Hansen, 2004: Database on wind characteristics-analyses of wind turbine design loads. Ris $\emptyset$ National Laboratory Rep., Ris $\varnothing-\mathrm{R}-1473,83$ pp.

Letson, F., S. C. Pryor, R. J. Barthelmie, and W. Hu, 2018: Observed gust wind speeds in the coterminous United States, and their relationship to local and regional drivers. J. Wind Eng. Ind. Aerodyn., 173, 199-209, https://doi.org/10.1016/j.jweia.2017.12.008.

Li, Q. S., L. Zhi, and F. Hu, 2010: Boundary layer wind structure from observations on a $325 \mathrm{~m}$ tower. J. Wind Eng. Ind. Aerodyn., 98, 818-832, https://doi.org/10.1016/j.jweia.2010.08.001.

Li, Y., K. Togbenou, H. Xiang, and N. Chen, 2017: Simulation of non-stationary wind velocity field on bridges based on Taylor series. J. Wind Eng. Ind. Aerodyn., 169, 117-127, https:// doi.org/10.1016/j.jweia.2017.07.005.

Lubitz, W. D., 2009: Effects of tower shadowing on anemometer data. Proc. 11th Americas Conf. on Wind Engineering, San Juan, PR, IAWE, http://www.iawe.org/Proceedings/11ACWE/ 11ACWE-Lubitz.pdf.

Manwell, J. F., J. G. McGowan, and A. L. Rogers, 2010: Wind Energy Explained: Theory, Design and Application. 2nd ed. John Wiley and Sons, 704 pp.

Mason, M. S., G. S. Wood, and D. F. Fletcher, 2010: Numerical investigation of the influence of topography on simulated downburst wind fields. J. Wind Eng. Ind. Aerodyn., 98, 21-33, https://doi.org/10.1016/j.jweia.2009.08.011.

Mikkelsen, T., S. E. Larsen, H. E. Jørgensen, P. Astrup, and X. G. Larsén, 2017: Scaling of turbulence spectra measured in strong shear flow near the Earth's surface. Physica Scr., 92, 124002, https://doi.org/10.1088/1402-4896/aa91b2.

Monin, A. S., and A. M. Obukhov, 1954: Basic laws of turbulent mixing in the atmosphere near the ground. Tr. Geofiz. Inst., Akad. Nauk SSSR, 24, 163-187.

Munger, J. W., H. W. Loescher, and H. Luo, 2012: Measurement, tower, and site design considerations. Eddy Covariance, M. Aubinet, T. Vesala, and D. Paple, Eds., Springer, 21-58.

Nielsen, M., G. C. Larsen, J. Mann, S. Ott, K. S. Hansen, and B. J. Pedersen, 2003: Wind simulation for extreme and fatigue loads. Ris $\varnothing$ National Laboratory Rep. Ris $\varnothing-R-1437,104$ pp.

NOAA, 1998: Automated Surface Observing System (ASOS) user's guide. NOAA Tech. Rep., 61 pp.

- 2004: Automated Surface Observing System (ASOS) release note, software version 2.79. NOAA Tech. Rep., 7 pp.

Oke, T. R., 1987: Boundary Layer Climates. 2nd ed. Routledge, $435 \mathrm{pp}$.

Pineda, N., O. Jorba, J. Jorge, and J. M. Baldasano, 2004: Using NOAA AVHRR and SPOT VGT data to estimate surface parameters: Application to a mesoscale meteorological model. Int. J. Remote Sens., 25, 129-143, https://doi.org/ 10.1080/0143116031000115201.

Pryor, S. C., R. J. Barthelmie, N. E. Clausen, M. Drews, N. MacKellar, and E. Kjellström, 2012: Analyses of possible changes in intense and extreme wind speeds over northern Europe under climate change scenarios. Climate Dyn., 38, 189-208, https://doi.org/10.1007/s00382-010-0955-3.

Simiu, E., R. Wilcox, F. Sadek, and J. J. Filliben, 2003: Wind speeds in ASCE 7 standard peak-gust map: Assessment. J. Struct. Eng., 129, 427-439, https://doi.org/10.1061/ (ASCE)0733-9445(2003)129:4(427).

Solari, G., 1993: Gust buffeting. II: Dynamic alongwind response. J. Struct. Eng., 119, 383-398, https://doi.org/10.1061/(ASCE) 0733-9445(1993)119:2(383). 
Suomi, I., T. Vihma, S.-E. Gryning, and C. Fortelius, 2013: Windgust parametrizations at heights relevant for wind energy: A study based on mast observations. Quart. J. Roy. Meteor. Soc., 139, 1298-1310, https://doi.org/10.1002/qj.2039.

Taylor, S. W., B. M. Wotton, M. E. Alexander, and G. N. Dalrymple, 2004: Variation in wind and crown fire behaviour in a northern jack pine-black spruce forest. Can. J. For. Res., 34, 1561-1576, https://doi.org/10.1139/x04-116.

Thorarinsdottir, T. L., and M. S. Johnson, 2012: Probabilistic wind gust forecasting using nonhomogeneous Gaussian regression. Mon. Wea. Rev., 140, 889-897, https://doi.org/10.1175/MWRD-11-00075.1.

Tieleman, H. W., 1992: Wind characteristics in the surface layer over heterogeneous terrain. J. Wind Eng. Ind. Aerodyn., 41, 329-340, https://doi.org/10.1016/0167-6105(92)90427-C.

Verheij, F. J., J. W. Cleijne, and J. A. Leene, 1992: Gust modelling for wind loading. J. Wind Eng. Ind. Aerodyn., 42, 947-958, https://doi.org/10.1016/0167-6105(92)90101-F.

Vickery, P. J., D. Wadhera, J. Galsworthy, J. A. Peterka, P. A. Irwin, and L. A. Griffis, 2010: Ultimate wind load design gust wind speeds in the United States for use in ASCE-7. J. Struct.
Eng., 136, 613-625, https://doi.org/10.1061/(ASCE)ST.1943541X.0000145.

Welch, P., 1967: The use of fast Fourier transform for the estimation of power spectra: A method based on time averaging over short, modified periodograms. IEEE Trans. Audio Electroacoust., 15, 70-73, https://doi.org/10.1109/ TAU.1967.1161901.

Wieringa, J., 1973: Gust factors over open water and built-up country. Bound.-Layer Meteor., 3, 424-441, https://doi.org/ 10.1007/BF01034986.

WMO, 2012: Measurement of surface wind. Guide to meteorological instruments and methods of observation, WMO-No. 8 , 2008 edition Updated in 2010, World Meteorological Organization.

Young, G. S., and L. Kristensen, 1992: Surface-layer gusts for aircraft operation. Bound.-Layer Meteor., 59, 231-242, https:// doi.org/10.1007/BF00119814.

Zhang, L.-L., J. Li, and Y. Peng, 2008: Dynamic response and reliability analysis of tall buildings subject to wind loading. J. Wind Eng. Ind. Aerodyn., 96, 25-40, https://doi.org/10.1016/ j.jweia.2007.03.001. 